\title{
The Adverse Impact of Muddy Laminae on Conventional SAGD Performance and Improvement Strategy with the Multilateral Well Pattern
}

\author{
Yang Yu $\mathbb{D}^{1}$, Shangqi Liu, ${ }^{1}$ Yu Bao $\mathbb{D}^{,}{ }^{1}$ Lixia Zhang, ${ }^{1}$ Jia Xie, ${ }^{2}$ Yang Liu, ${ }^{1}$ Guangyue Liang, \\ and Jiuning Zhou ${ }^{1}$ \\ ${ }^{1}$ Research Institute of Petroleum Exploration and Development, PetroChina, Beijing 100083, China \\ ${ }^{2}$ Liaohe Oilfield Company, PetroChina, Panjin, 124010 Liaoning, China \\ Correspondence should be addressed to Yang Yu; yystzp@hotmail.com and Yu Bao; baoyu03@petrochina.com.cn
}

Received 18 May 2021; Accepted 16 August 2021; Published 1 September 2021

Academic Editor: Shengnan Nancy Chen

Copyright (c) 2021 Yang Yu et al. This is an open access article distributed under the Creative Commons Attribution License, which permits unrestricted use, distribution, and reproduction in any medium, provided the original work is properly cited.

With further progress of Steam-Assisted Gravity Drainage (SAGD) technology, a growing number of oil sands or heavy oil reservoirs were put into production in an efficient way. However, owing to the existence of muddy laminae within reservoirs, there are challenges associated with the expansion of the steam chamber and oil drainage during the SAGD process. The purpose of this study is to evaluate the adverse impact of muddy laminae on conventional SAGD performance and introduce an improvement strategy with multilateral well patterns to reduce the adverse impact and improve the performance. In the research reported here, the reservoir numerical simulation approach is applied to conduct the research. The analysis conducted on a prototypical reservoir reveals that the steam chamber may expand slowly in some sections due to the poor capacity of heat and mass transfer, and the expansion of the steam chamber is relatively uneven along the wellbore, when the muddy laminae are existing in the formation. The influence level of the muddy laminae on conventional SAGD performance under different distribution modes is different, but the adverse effect is mainly reflected in the delay of peak oil production, the decrease in peak oil production, the decrease in steam chamber volume, and the increase in the cumulative steam oil ratio (mainly in early and middle stages of the SAGD process). On the basis of aforementioned researches, the improvement strategy with two different multilateral well patterns, planar multilateral well and upward multilateral well, is introduced to improve the SAGD performance. The results indicate that the combination of a planar multilateral injector and planar multilateral producer has the best performance. By adopting such kind of combination, the recovery factor can be increased from $31.36 \%$ to $47.08 \%$, and the cumulative steam oil ratio can be decreased from $5.29 \mathrm{~m}^{3} / \mathrm{m}^{3}$ to $4.64 \mathrm{~m}^{3} / \mathrm{m}^{3}$ under the combined distribution mode of muddy laminae. It can be known that the branches of the planar multilateral well are very helpful for the expansion of the steam chamber and oil drainage, once the heat connection between branches of the injector and producer is well established. Overall results show that the multilateral well pattern is promising for SAGD applications at oil sands or heavy oil reservoirs which are rich in muddy laminae.

\section{Introduction}

Oil sands or heavy oil reservoirs are considered to be the important part of unconventional resources [1-3]. And SAGD technology is widely used in the recovery process of aforementioned resources [4-8]. Over the past few years, SAGD technology has achieved great success in several large-scale commercial projects all over the world, such as Mackay River oil sands in Canada or Shuguang SAGD project of the Liaohe oilfield in China $[9,10]$. However, low-permeable shaly or muddy barriers are commonly found in reservoirs where the SAGD technology is adopted [11-13]. The existence of barriers may affect the expansion of the steam chamber and the recovery performance during the SAGD process.

In recent years, many scholars have carried out a series of studies which are related to the influence of shale barriers 
during the SAGD process. Yang and Butler [14] studied the effect of a horizontal interlayer on the SAGD process through a two-dimensional physical experiment, and the results indicated that a short interlayer does not have the significant effect on the overall recovery performance, while the oil production will be decreased if the long interlayer exists. Shin and Choe [15] built different numerical simulation models to study the impact of physical parameters and spatial location of shale interlayers on the SAGD process and found that the shale interlayer acts as a flow barrier. Wang [16] employed the numerical simulation method to study the influence of the muddy interlayer on the recovery performance of the SAGD process, and the results show that the thick muddy interlayer with low permeability has strong blocking capacity. Xia et al. [17] considered the variation of physical and thermal properties of interlayers and then conducted the related numerical simulation runs, in order to study the impact of interlayers on the steam chamber and production profile of the SAGD process; the results reveal that the length of the interlayer has the greatest influence on SAGD performance, while the thermal conductivity of the interlayer has less impact than other properties. Huang et al. [18] studied the influence of multiple shale interlayers on the steam chamber and production profile of the SAGD process by combining a physical experiment method and numerical simulation approach; the results show that the key factor is the length of the first interlayer. $\mathrm{Ma}$ and Leung $[13,19]$ designed various distribution scenarios of the shale interlayer including the variation of threedimensional spatial distribution and geological characteristics and conducted the related numerical simulation runs; the results indicate that the production rate decreases significantly when the steam chamber touches the interlayer, and this phenomenon will last until the steam chamber extends through the entire interlayer. In 2020, case studies of the Fengcheng SAGD project in China were carried out by Wang et al. and Liu et al. [20,21], in order to compare the SAGD performance under different distribution patterns through a statistical analysis approach and numerical simulation method; the results show that the flow capacity of fluid is weak at the area where interlayers exist, and the remaining oil zone with high oil saturation is formed above the interlayer.

Aforementioned works reveal that low-permeable zones in the reservoir, such as the shale interlayer, act as flow barriers for the fluids within the reservoir (as depicted in Figure 1). And it also affects heat transfer performance in the steam chamber. Previous studies mainly focus on extralow permeability or impermeable barriers which are always continuously distributed [22, 23]. However, muddy laminae, such as muddy laminae in Mackay River oil sands, are always distributed in a discrete way within a certain range. Unlike the shale barriers in Long Lake oil sands or Fengcheng extraheavy oil development area, such kind of muddy laminae does not act as continuous long flow barriers but block the flow of fluids in a discrete way. Therefore, it is necessary to study the adverse impact of muddy laminae on SAGD performance (including the impact in the direction along the wellbore), which

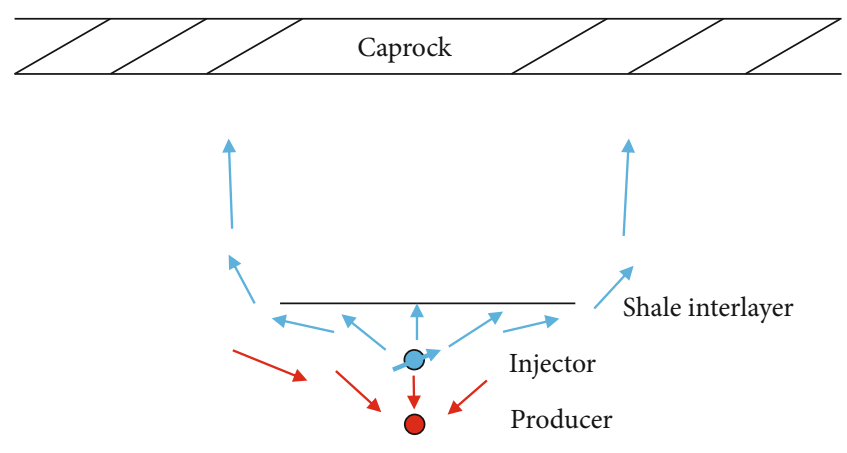

Figure 1: Schematic of the shale interlayer acting as a flow barrier.

is the cornerstone of the technical strategy to improve the overall performance in the future.

To improve the performance and adaptability of SAGD technology, scholars have proposed a variety of strategies [24-28]. For the development of oil sands or heavy oil reservoirs, some operating optimization strategies and variants of SAGD technology have achieved good results, but there are still some limitations. For example, high-pressure SAGD technology may destroy the shale barriers and caprock at the same time; solvent-based processes are the promising applications for enhancing heavy oil recovery [29], but the solvent-assisted SAGD technology is very costly.

In this paper, the improvement strategy with multilateral well patterns is introduced to minimize the adverse impact of muddy laminae. With the development of horizontal well completion technology and the popularization of 3D seismic technology, multilateral well systems and their applications have developed rapidly [30-32]. A multilateral well has a vertical, inclined, or horizontal main wellbore, and there is one or more branches connected to the main wellbore. The connection point between the branches and the main wellbore can be located at any position on the main wellbore. It is a significant motivation to take advantage of the multilateral well for reducing the risk of heterogeneity which is brought by muddy laminae. Multilateral wells have been widely used as production wells in various types of reservoirs, and several multilateral well patterns have been designed for different purposes [33-37]. As for the steam injection well, Liu et al. [38] proposed a kind of multilateral well pattern to inject steam towards reservoirs.

This paper focuses on the research of adverse impact of muddy laminae with different distribution modes on conventional SAGD performance, and the suitable improvement strategy with multilateral well patterns is proposed. In the construction process of the reservoir models, the random discrete distribution of muddy laminae in a certain range is considered, in order to capture the characteristic shown in real reservoirs. Thus, the influence of the muddy laminae with different proportion of the distribution or permeability on conventional SAGD performance under different distribution modes is studied, which is crucial to further research. Under some certain distribution modes, the significant adverse effect could be brought by low-permeable muddy laminae with high frequency. In these cases, it is 
necessary to put forward effective improvement measures. On the basis of reservoir models under different distribution modes of muddy laminae, the improvement strategy with two different multilateral well patterns, planar multilateral well and upward multilateral well, is introduced to improve the SAGD performance. Overall results show that the multilateral well pattern is promising for SAGD applications at oil sands or heavy oil reservoirs which are rich in muddy laminae. The findings of this study could help for better understanding of the adverse impact of muddy laminae on conventional SAGD performance and illustrate the potential for application of the multilateral well pattern to help reservoir engineers make better design of this significant thermal recovery technology for oil sands or heavy oil reservoirs.

This paper is structured as follows: first, the prototype reservoir is described; second, the reservoir numerical simulation approach and related model are introduced; next, various numerical models are developed to investigate the adverse impact of muddy laminae on conventional SAGD performance; furthermore, on the basis of the numerical models under different distribution modes of muddy laminae, the improvement strategy with multilateral well patterns is proposed and studied, in order to minimize the adverse impact of muddy laminae and improve SAGD performance; lastly, the key conclusions are summarized.

\section{Prototype Reservoir}

As shown in Table 1, typical reservoir characteristics of MacKay River oil sands in Canada are applied in this study to describe the prototype reservoir. In this area, the average values of initial reservoir temperature and initial reservoir pressure are $6^{\circ} \mathrm{C}$ and $220 \mathrm{kPa}$, respectively. The mean value of initial oil saturation is 0.8 , while the average thickness of MacKay River oil sands is $20 \mathrm{~m}$. The mean porosity and horizontal permeability of formation with sand stone are 0.34 and $2600 \mathrm{mD}$, respectively, while the anisotropy factor (ratio of vertical permeability to horizontal permeability) is 0.3 . The formation compressibility is $2 \times 10^{-6} 1 / \mathrm{kPa}$, and the rock heat capacity is $2.39 \times 10^{6} \mathrm{~J} /\left(\mathrm{m}^{3} \cdot{ }^{\circ} \mathrm{C}\right)$. The thermal conductivity of rock, bitumen, water, and gas are $4.5 \times 10^{5}$, $8.04 \times 10^{3}, \quad 5.53 \times 10^{4}, \quad$ and $2.07 \times 10^{3} \mathrm{~J} /\left(\mathrm{m}^{3} \cdot{ }^{\circ} \mathrm{C}\right)$, respectively.

The properties of the crude oil in this area are listed in Table 2. And the relation between bitumen viscosity and temperature in MacKay River oil sands is shown in Figure 2. It can be seen from Figure 2 that bitumen viscosity decreases dramatically as the temperature increases. At the temperature of the steam chamber, the viscosity is less than $10 \mathrm{mPa} \cdot \mathrm{s}$.

\section{Reservoir Simulation Model}

In this study, a commercial thermal numerical simulator $\left(\right.$ CMG STARS $^{\mathrm{TM}}$ ) [39] is employed to do the related research. A three-dimensional view of the basic reservoir simulation model is shown in Figure 3.

As shown in Figure 3, two horizontal wells, steam injecting well and producing well, are placed in a parallel manner at the bottom of the model, and the vertical distance between the two wells is $5 \mathrm{~m}$. The length in the $X$-direction of the reservoir simulation model is $125 \mathrm{~m}$ considering the actual distance between two adjacent SAGD well pairs in MacKay River oil sands. And the $Y$-directional length of the reservoir simulation model is $850 \mathrm{~m}$ considering the actual wellbore length in MacKay River oil sands. The height of the reservoir simulation model is set as $20 \mathrm{~m}$ according to the average thickness of MacKay River oil sands. Eventually, the overall size of the reservoir simulation model is $125 \mathrm{~m} \times 850 \mathrm{~m} \times$ $20 \mathrm{~m}$, and the grid size is $5 \mathrm{~m}$ in both $X$ and $Y$ directions and $1 \mathrm{~m}$ in the $Z$ direction. In total, 85,000 grids are discretized. The preheating period lasts 150 days, and the production period lasts 20 years with the consideration of the realistic SAGD project. In the production period, steam (95\% quality, $212.4^{\circ} \mathrm{C}, 2000 \mathrm{kPa}$ ) is continuously injected into the steam chamber with an upper injector. And it is noteworthy that the maximum steam rate of the production well is constrained to $5.0 \mathrm{~m}^{3} /$ day CWE (cold water equivalent), in order to mimic steam trap control at the production well.

For multiphase flow in porous media, Darcy's law can be described as follows:

$$
\mathbf{u}_{i}=-\frac{\mathbf{K}_{i}}{\mu_{i}} \nabla \boldsymbol{\Phi}_{i} .
$$
[40]:

In equation (1), potential can be described as follows

$$
\boldsymbol{\Phi}=\left(z-z_{\text {datum }}\right) g+\int_{P_{\text {datum }}}^{P} \frac{d P}{\rho} .
$$

Conductive heat transfer in the reservoir obeys Fourier's law [41]:

$$
\mathbf{Q}=-\mathbf{k}_{\mathrm{th}} \nabla T
$$

Then, the main governing equations of the reservoir simulation model and equations of material balance and energy balance for all phases are given by [42]

$$
\begin{aligned}
& \nabla \cdot\left[\frac{K_{\mathrm{abs}} K_{\mathrm{ro}} R_{\mathrm{so}}}{\mu_{\mathrm{o}} B_{\mathrm{o}}}\left(\nabla P_{\mathrm{o}}-\rho_{\mathrm{o}} g \nabla z\right)\right. \\
& \quad+\frac{K_{\mathrm{abs}} K_{\mathrm{rw}} R_{\mathrm{sw}}}{\mu_{\mathrm{w}} B_{\mathrm{w}}}\left(\nabla P_{\mathrm{w}}-\rho_{\mathrm{w}} g \nabla z\right) \\
& \left.\quad+\frac{K_{\mathrm{abs}} K_{\mathrm{rg}}}{\mu_{\mathrm{g}} B_{\mathrm{g}}}\left(\nabla P_{\mathrm{g}}-\rho_{\mathrm{g}} g \nabla z\right)\right] \\
& =\frac{\partial}{\partial t}\left[\left(\frac{S_{\mathrm{o}} R_{\mathrm{so}}}{B_{\mathrm{o}}}+\frac{S_{\mathrm{w}} R_{\mathrm{sw}}}{B_{\mathrm{w}}}+\frac{S_{\mathrm{g}}}{B_{\mathrm{g}}}\right) \phi\right]+\frac{R_{\mathrm{so}} q_{\mathrm{o}}}{B_{\mathrm{o}}}+\frac{q_{\mathrm{fg}}}{B_{\mathrm{g}}},
\end{aligned}
$$


TABLE 1: Typical reservoir characteristics of MacKay River oil sands.

\begin{tabular}{lcc}
\hline Item & Value \\
\hline Initial reservoir temperature $\left({ }^{\circ} \mathrm{C}\right)$ & 6 \\
Initial reservoir pressure $(\mathrm{kPa})$ & 220 \\
Initial oil saturation (fraction) & 0.8 \\
Thickness $(\mathrm{m})$ & 20 \\
Porosity (fraction) & 0.34 \\
Horizontal permeability of sand stone $(\mathrm{mD})$ & 2600 \\
Ratio of vertical permeability to horizontal permeability (fraction) & 0.3 \\
Formation compressibility $(1 / \mathrm{kPa})$ & $2 \times 10^{-6}$ \\
Rock heat capacity $\left(\mathrm{J} /\left(\mathrm{m}^{3} \cdot{ }^{\circ} \mathrm{C}\right)\right)$ & $2.39 \times 10^{6}$ \\
Rock thermal conductivity $\left(\mathrm{J} /\left(\mathrm{m}^{3} \cdot{ }^{\circ} \mathrm{C}\right)\right)$ & $4.5 \times 10^{5}$ \\
Bitumen thermal conductivity $\left(\mathrm{J} /\left(\mathrm{m}^{3} \cdot{ }^{\circ} \mathrm{C}\right)\right)$ & $8.04 \times 10^{3}$ \\
Water thermal conductivity $\left(\mathrm{J} /\left(\mathrm{m}^{3} \cdot{ }^{\circ} \mathrm{C}\right)\right)$ & $5.53 \times 10^{4}$ \\
Gas thermal conductivity $\left(\mathrm{J} /\left(\mathrm{m}^{3} \cdot{ }^{\circ} \mathrm{C}\right)\right)$ & $2.07 \times 10^{3}$ \\
\hline
\end{tabular}

Table 2: Properties of the crude oil applied in this study.

\begin{tabular}{|c|c|c|}
\hline \multicolumn{2}{|l|}{ Item } & Value \\
\hline \multicolumn{2}{|c|}{ Density @15.6 $6^{\circ} \mathrm{C}\left(\mathrm{kg} / \mathrm{m}^{3}\right)$} & 1005 \\
\hline \multicolumn{2}{|c|}{ API gravity } & 9.3 \\
\hline \multicolumn{2}{|c|}{ Viscosity@20ㄷ (mPa.s) } & $9.53 \times 10^{5}$ \\
\hline \multirow{4}{*}{ SARA composition (wt\%) } & Saturates & 18.1 \\
\hline & Aromatics & 39.4 \\
\hline & Resins & 32.4 \\
\hline & Asphaltenes & 10.1 \\
\hline
\end{tabular}

$$
\begin{aligned}
& \frac{\partial}{\partial x}\left(-k_{\text {th }} \frac{\partial T}{\partial x}+\sum_{i=1}^{n_{\mathrm{p}}} u_{i, x} \rho_{i} h_{i}\right)+\frac{\partial}{\partial y}\left(-k_{\mathrm{th}} \frac{\partial T}{\partial y}+\sum_{i=1}^{n_{\mathrm{p}}} u_{i, y} \rho_{i} h_{i}\right) \\
& \quad+\frac{\partial}{\partial z}\left(-k_{\mathrm{th}} \frac{\partial T}{\partial z}+\sum_{i=1}^{n_{\mathrm{p}}} u_{i, z} \rho_{i}\left[\frac{h_{i}+g z}{J g_{c}}\right]\right) \\
& =\frac{\partial}{\partial t}\left[M_{\mathrm{r}}\left(T-T_{\mathrm{ref}}\right)(1-\phi)\right. \\
& \left.\quad+\left(S_{\mathrm{o}} \rho_{\mathrm{o}} U_{\mathrm{o}}+S_{\mathrm{w}} \rho_{\mathrm{w}} U_{\mathrm{w}}+S_{\mathrm{g}} \rho_{\mathrm{g}} U_{\mathrm{g}}\right) \phi\right]+Q_{\mathrm{I}} .
\end{aligned}
$$

Such set of coupled partial differential equations are solved by the commercial thermal numerical simulator $\left(\mathrm{CMG} \mathrm{STARS}^{\mathrm{TM}}\right.$ ) [39]. CMG STARS ${ }^{\mathrm{TM}}$ uses the finite volume approach to solve the related governing equations which are then solved by using Newton's method with an implicit time integrator to march through time [42].

\section{Results and Discussion}

4.1. The Impact of Muddy Laminae on Conventional SAGD Performance. In this study, four different distribution modes of muddy laminae are designed to investigate their impact on conventional SAGD performance. The base model is a homogeneous model, while the others contain the muddy laminae under different distribution modes. As shown in Figure 4, the first distribution mode is that the muddy laminae are distributed above the injector and the muddy laminae are close to the top of the formation. The second distribution mode is that the muddy laminae are distributed above the injector, but the muddy laminae are close to the injector. And the third distribution mode is that the muddy laminae are distributed between the injector and producer. Lastly, the fourth distribution mode is a combined distribution mode which includes aforementioned three modes.

Muddy laminae, such as muddy laminae in Mackay River oil sands, are always distributed in a discrete way within a certain range (as depicted in Figure 5). To capture such kind of characteristic, the random discrete distribution of muddy laminae in a certain range was considered when establishing the related model (as shown in Figure 6). Take the second mode as an example (Figure 6), the red parts represent the sand stone whose physical parameters have been mentioned before, while the blue parts represent the muddy laminae with different permeability (the value is less than that of sand stone) and thermal conductivity $\left(3 \times 10^{5} \mathrm{~J} /\left(\mathrm{m}^{3} \cdot{ }^{\circ} \mathrm{C}\right)\right)$. The concept of the proportion of the distribution of the muddy laminae is introduced, which refers to the ratio of the area of muddy laminae to the area of the related defined zone.

4.1.1. The Impact of Muddy Laminae Distributed above the Injector. Under the first distribution mode, various scenarios with different proportion of the distribution and permeability of the muddy laminae are conducted. The simulation results are shown in Figure 7. In Figure 7, a homogeneous case refers to the reservoir without muddy laminae, while the $10 \mathrm{P}-10 \mathrm{mD}$ means that the proportion of the distribution and permeability of the muddy laminae are $10 \%$ and $10 \mathrm{mD}$, respectively, and the rest may be deduced by analogy. It is noteworthy that if the denominator is the area of the whole 


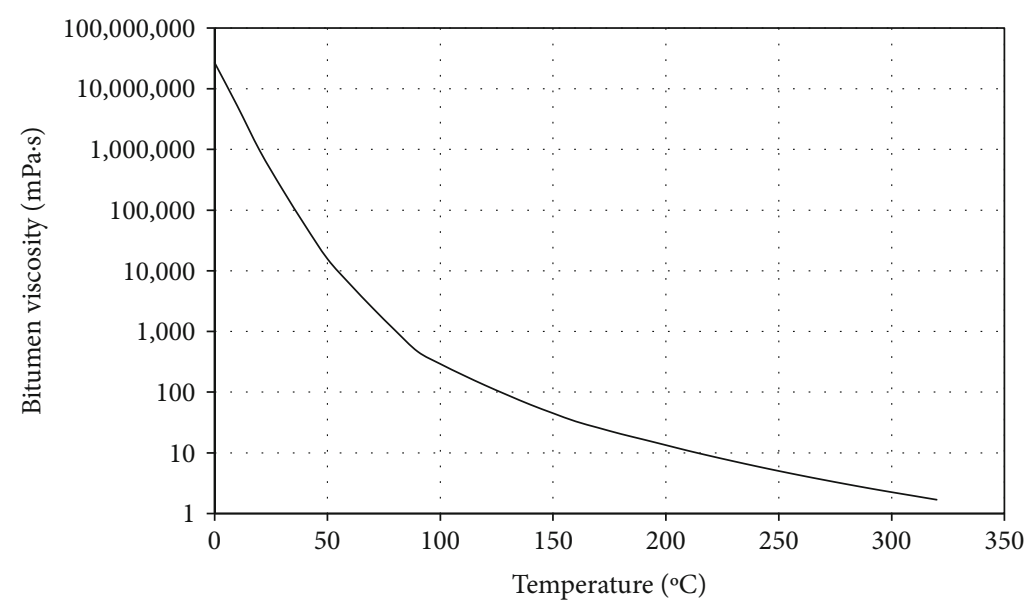

FIgURE 2: The curve of the relation between bitumen viscosity and temperature.

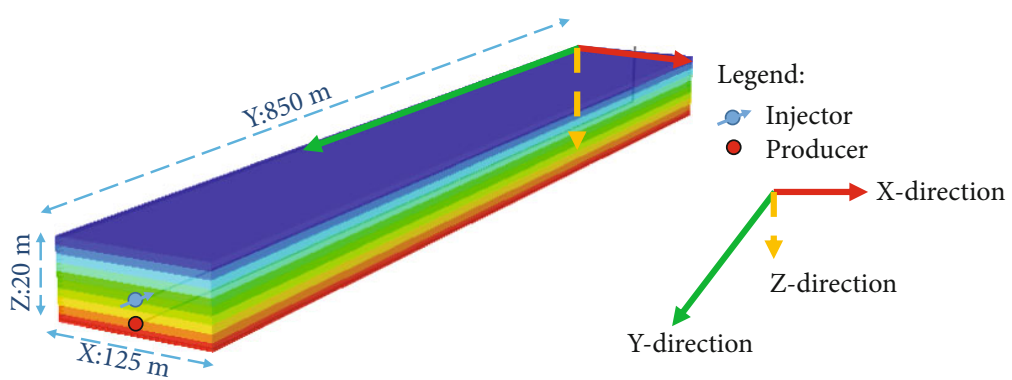

Figure 3: Three-dimensional view of the reservoir simulation model.
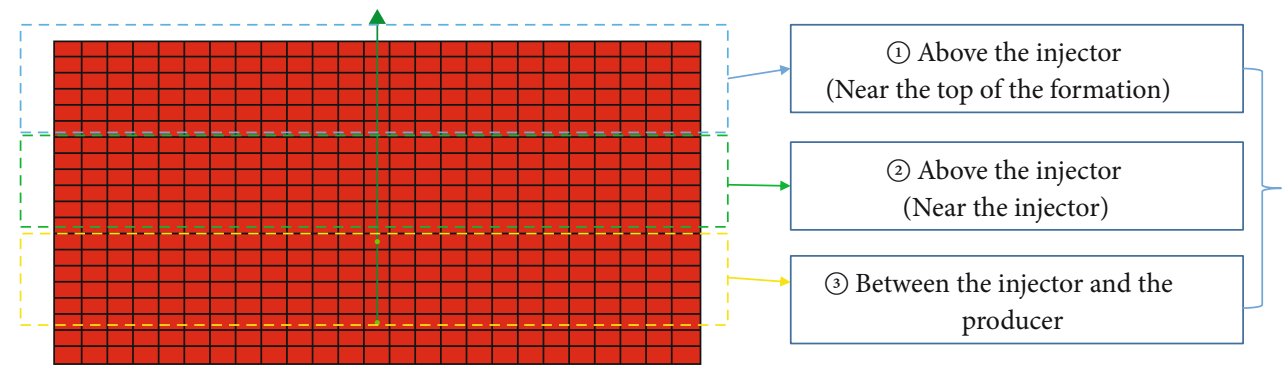

(4) Combined distribution

FIgURE 4: Schematic diagram of four different distribution modes.

reservoir, the proportion of the distribution of the muddy laminae is just $3 \%$ in the $10 \mathrm{P}$ case and so forth.

It can be seen from Figure 7 that performance indicators change slightly under the first distribution mode, no matter how the conditions change within the scope of the study. With the increase in proportion of the distribution or the decrease in permeability of the muddy laminae, the performance indicators tend to become worse. But in general, when the muddy laminae are distributed above the injector (close to the top of the formation), they have no significant impact on the conventional SAGD performance.

For the second distribution mode, several cases with different proportion of the distribution and permeability of the muddy laminae are simulated. Taken as a whole, when the proportion of the distribution of muddy laminae is relatively low, the results are similar to those of the first distribution mode. However, when the proportion of distribution is relatively high, muddy laminae will have more prominent impact on SAGD performance. The representative results are selected for comparison (Figure 8).

As shown in Figure 8, when the muddy laminae are distributed above the injector (close to the injector) and proportion of the distribution is $30 \%$, if they have a high permeability (such as $1000 \mathrm{mD}$ ), their impact on the SAGD performance is very slight; however, when the permeability is lower than $50 \mathrm{mD}$, the impact becomes relatively significant (mainly in early and middle stages of the SAGD process). And when the permeability of muddy laminae is $10 \mathrm{mD}$, if the proportion of the distribution is relatively low (less than 20\%), their impact on the SAGD performance is very slight; however, as the proportion increases, the impact tends to become more prominent. Overall, when 


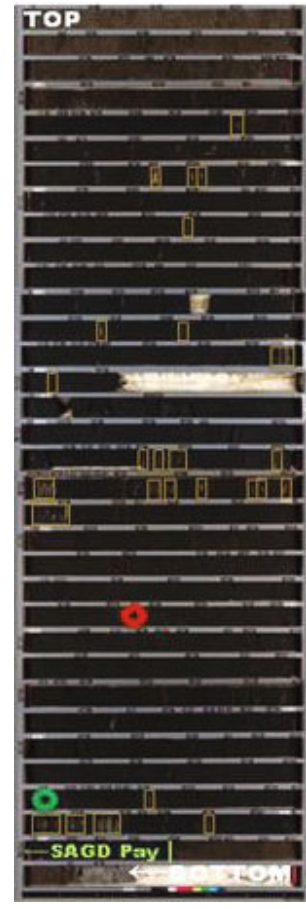

(a)

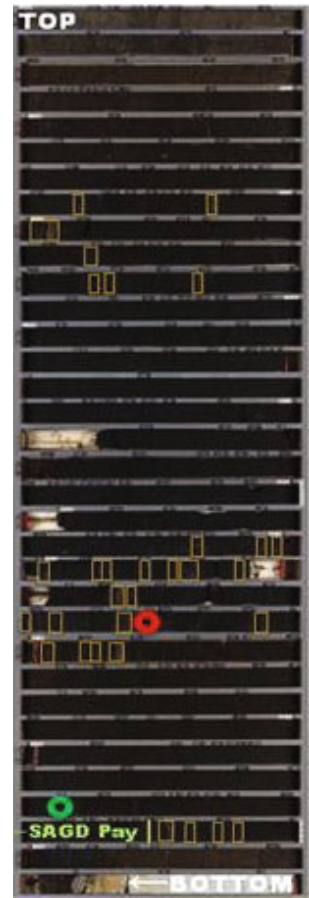

(c)

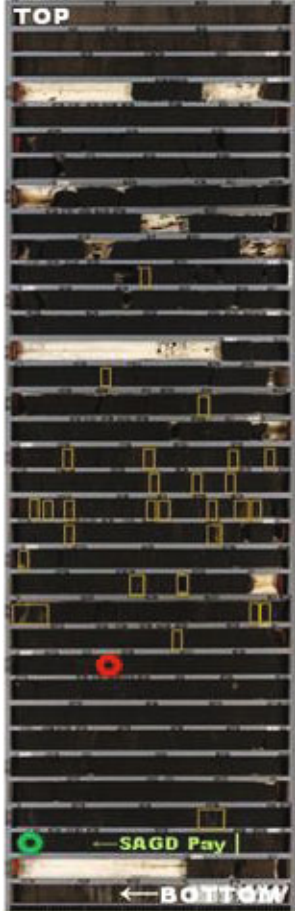

(b)

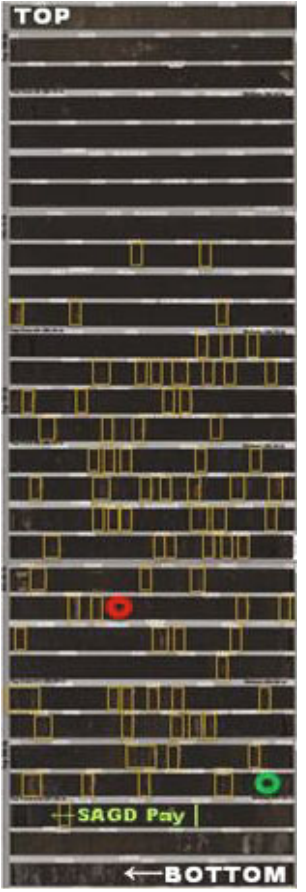

(d)

Figure 5: Photos of cores from four observation wells in Mackay River oil sands (modified from [43]).

the muddy laminae are distributed above the injector (close to the injector), the adverse effects are mainly reflected in the delay of peak oil production, the decrease in peak oil production, and the increase in the cumulative steam oil ratio in early and middle stages of the SAGD process; however, the recovery factor and final cumulative steam oil ratio are very close.
4.1.2. The Impact of Muddy Laminae Distributed between the Injector and Producer. For the third distribution mode, several cases with different proportion of the distribution (ranging from $0 \%$ to $30 \%$ ) and permeability of the muddy laminae (ranging from $10 \mathrm{mD}$ to $1000 \mathrm{mD}$ ) are simulated. Some of the results are shown in Figures 9 and 10. As shown in Figures 9 and 10(a), when the muddy laminae are 


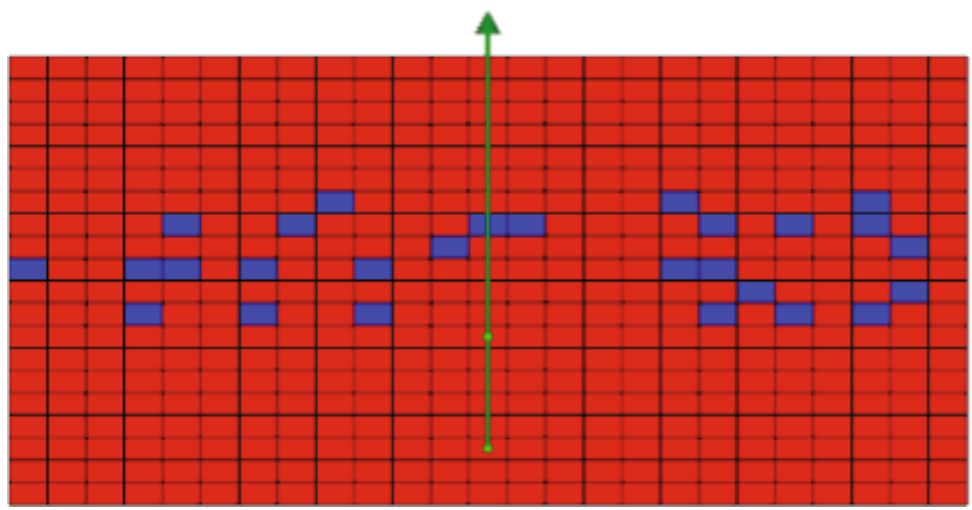

Muddy laminae

Sand stone

(a) Cross-sectional view

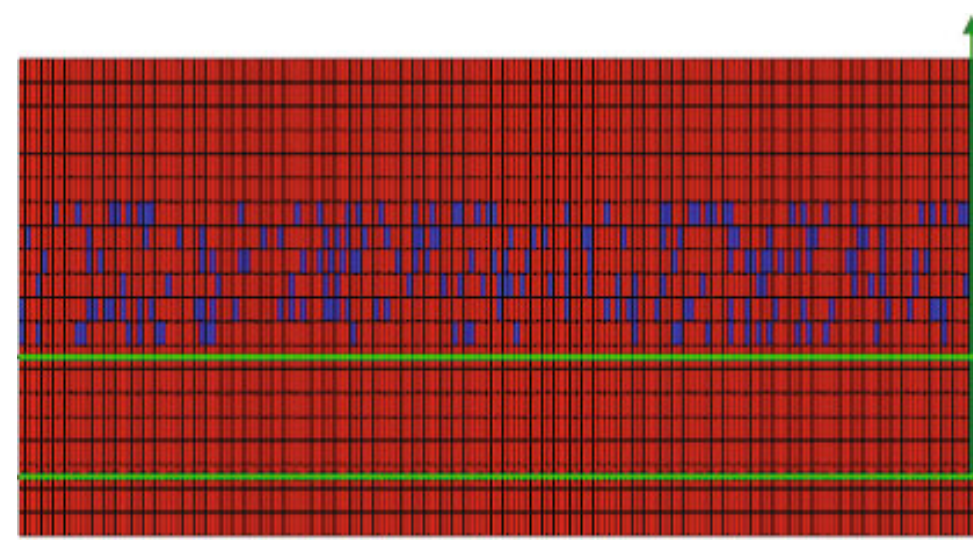

Muddy laminae

Sand stone

(b) Profile along the wellbore

Figure 6: Schematic diagram of the second distribution mode.

distributed between the injector and producer, if they have high permeability (such as $500 \mathrm{mD}$ or $1000 \mathrm{mD}$ ), their impact on the SAGD performance is slight, even in the condition with high proportion of the distribution; however, when the permeability is lower than $200 \mathrm{mD}$, the impact becomes relatively significant (in all stages of the SAGD process). When the permeability of muddy laminae is $10 \mathrm{mD}$, the reduction of the recovery factor can be reached $20 \%$ compared with that of the homogeneous case. And when the permeability of muddy laminae is $200 \mathrm{mD}$, if the proportion of the distribution is relatively low (less than 20\%), their impact on the SAGD performance is slight; however, as the proportion increases, the impact tends to become more prominent. If the proportion of the distribution is higher than $20 \%$, the time related to peak oil production is significantly increased and the peak oil production is significantly decreased compared with that of the homogeneous case. So do the recovery factor and the volume of the steam chamber. The recovery factor of the $30 \mathrm{P}-200 \mathrm{mD}$ model is reduced by $7.5 \%$ compared with that of the homogeneous model.
4.1.3. The Impact of the Combined Distribution Mode. The combined distribution mode infers that muddy laminae are both distributed above the injector and between the injector and producer. So if the denominator is the area of the whole reservoir, the proportion of the distribution of the muddy laminae is $9 \%$ in the $10 \mathrm{P}$ case and so forth. When the proportion of the distribution is relatively low, the impact is similar to that of the third distribution mode. However, when the muddy laminae exist with a high proportion, even if the muddy laminae have high permeability (such as $1000 \mathrm{mD}$ ), they will have the certain impact on SAGD performance (as shown in Figure 11).

When the permeability is lower than $200 \mathrm{mD}$, the impact on SAGD performance becomes very significant. The recovery factor of the $30 \mathrm{P}-200 \mathrm{mD}$ model is reduced by $13 \% \mathrm{com}$ pared with that of the homogeneous model. With the further reduction of permeability of the muddy laminae, the recovery factor is greatly reduced, even the daily oil production curve is still "climbing" (it means that the oil production does not reach the peak; see Figure 11(b)), and other 

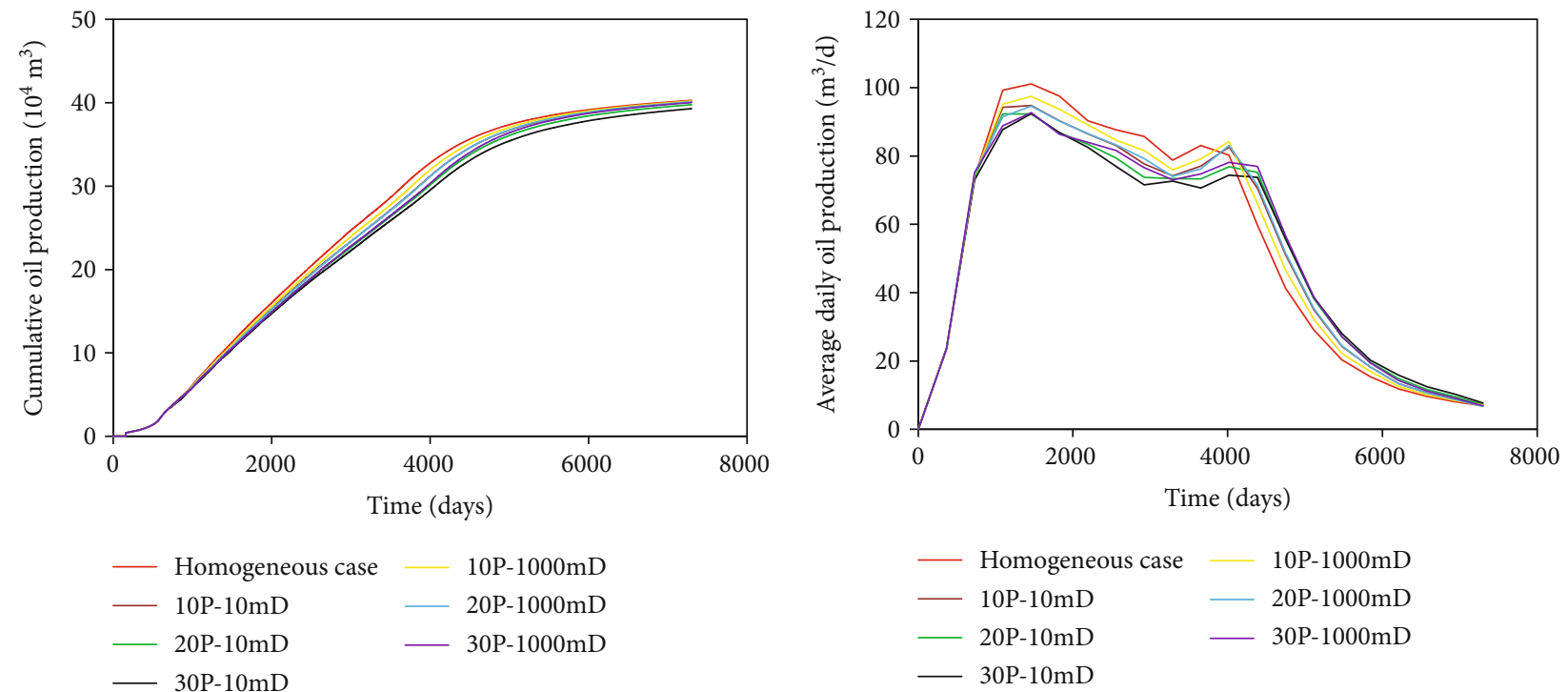

(a)

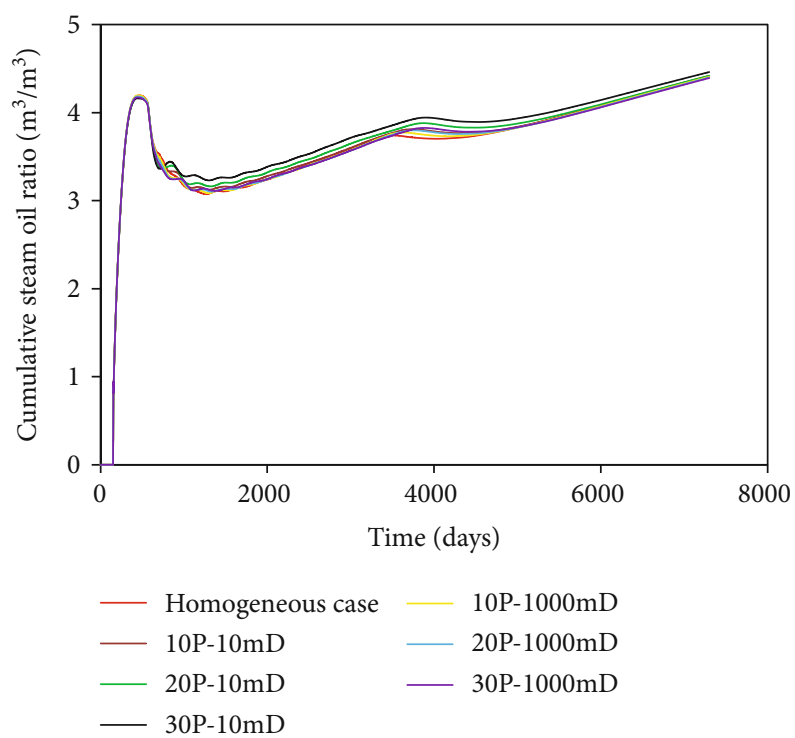

(c)

(d)

FIGURE 7: SAGD performance with different proportion of the distribution and permeability of the muddy laminae (first distribution mode): (a) cumulative oil production, (b) average daily oil production, (c) steam chamber volume, and (d) cumulative steam oil ratio.

performance indicators also significantly become worse (see Figures 11(a), 11(c), and 11(d)).

Three-dimensional expansion of the steam chamber with different cases is shown in Figure 12. It can be obviously seen from Figure 12 that the steam chamber develops more unevenly along the wellbore as the proportion of the distribution of the muddy laminae increases.

4.1.4. The Comparison between Different Distribution Modes. SAGD performance under different distribution modes is shown in Figures 13 and 14. As shown in Figure 13, when the permeability of muddy laminae is $10 \mathrm{mD}$ and the proportion of the distribution is $10 \%$, the SAGD performance of the four distribution modes is very close; among them, when the muddy laminae are distributed with the fourth mode (combined distribution mode), the adverse impact of muddy laminae on conventional SAGD performance is greater than others, as the results of higher proportion of the muddy laminae.

As shown in Figures 13 and 14, with the increase in proportion of the distribution, the difference of SAGD performance between the four modes becomes more prominent. It can be seen obviously from Figure 14 that the influence level of the adverse impact of different modes in descending order is as follows: fourth mode $>$ third mode $>$ second mode $>$ first mode.

When the muddy laminae are distributed above the injector (close to the top of the formation), the steam chamber expands well and develops relatively uniformly along the 


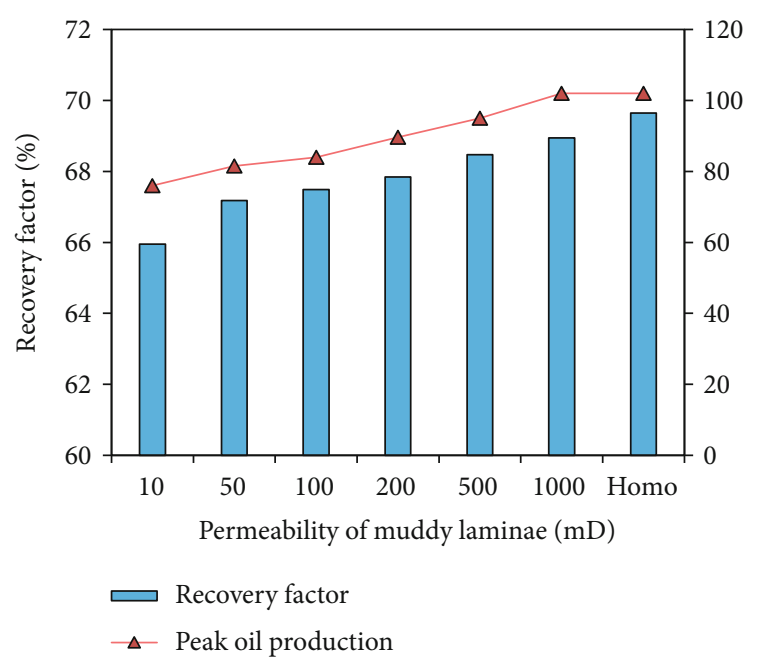

(a)

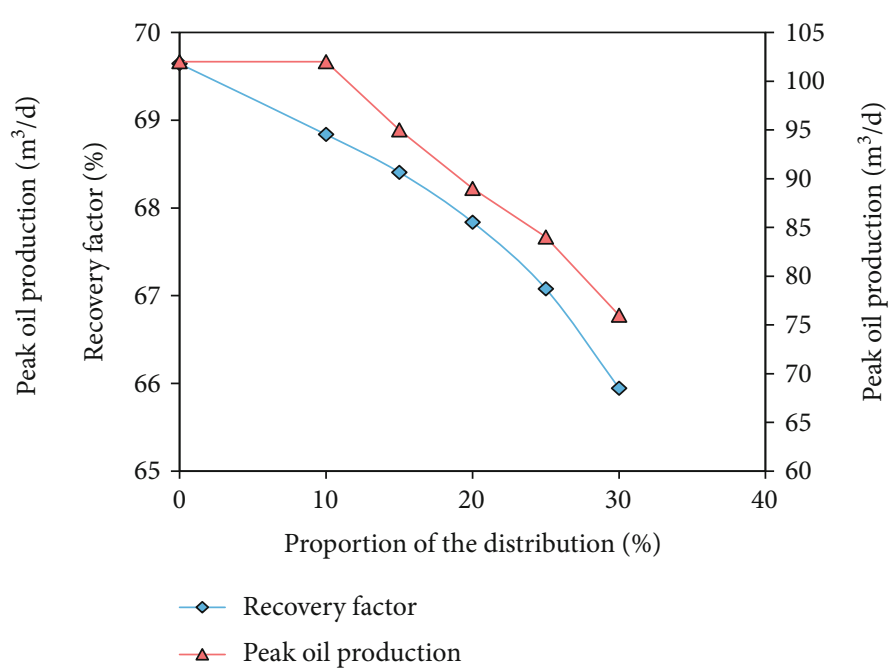

(b)

FIGURE 8: Recovery factor and peak oil production with different permeability and proportion of the distribution of the muddy laminae (second distribution mode): (a) different permeability (proportion $=30 \%$ ) and (b) different proportion (permeability $=10 \mathrm{mD}$ ).

wellbore; under this distribution mode, the well-developed steam chamber is formed before the steam reaches the location of the muddy laminae, so the adverse blocking effect of muddy laminae on fluid flow is relatively small. When the muddy laminae are distributed above the injector (close to the injector), the muddy laminae hinder the upward migration of steam and the drainage of crude oil, as soon as the production stage of the SAGD process starts; therefore, compared with the first mode, the development of the steam chamber is worse.

When the muddy laminae are distributed between the injector and producer, the steam chamber expands slowly in many sections due to the poor capacity of heat and mass transfer, and the expansion of the steam chamber is relatively uneven along the wellbore. Comparing the simulation results, it could be found that the muddy laminae distributed between the injector and producer, especially which are located at the middle part of the injector and producer, seriously affect the preheating effect of the start-up stage. Because the development of the steam chamber is delayed and the muddy laminae seriously hinder the oil drainage, the SAGD performance under the third mode is poor. When the mode is the combined distribution mode (fourth mode), the influence on SAGD performance shows similar characteristics to those of the third mode. But owing to the higher proportion of the muddy laminae, the influence degree is greater.

\subsection{Improvement Strategy with the Multilateral Well Pattern.} When the muddy laminae are distributed above the injector (close to the top of the formation), the performance indicators change slightly, no matter how the conditions change within the scope of the study. Under this distribution mode, the well-developed steam chamber is formed before the steam reaches the location of the muddy laminae, so the influence degree is lowest. SAGD performance of this distribution mode is very close to that of the homogeneous case, so that it is unnecessary to adopt the multilateral well pattern.

All the results of the four different distribution models show that the adverse impact of muddy laminae is insignificant, when the proportion of the distribution of muddy laminae is relatively low $(<20 \%)$ (note: for the three distribution modes except the combined distribution mode, when the proportion of the distribution of muddy laminae accounts for $20 \%$, it is equivalent to $6 \%$ if the denominator is the area of the whole reservoir). Meanwhile, when the permeability of muddy laminae is high (e.g., $500 \mathrm{mD}$ and $1000 \mathrm{mD}$ ), the adverse impact of muddy laminae is insignificant. Under such situations, it is unnecessary to adopt the multilateral well pattern. So the worst situations (permeability $=10 \mathrm{mD}$ and proportion $=30 \%$ ) for each distribution mode are considered in this study, when evaluating the performance of multilateral well patterns.

In this section, two kinds of multilateral well patterns are designed to improve the performance, as shown in Figure 15. One is the planar multilateral well which has 10 branches (length: $100 \mathrm{~m}$, spacing: $75 \mathrm{~m}$, and included angle between the branch and main wellbore: $30^{\circ}$ ) connected to the main wellbore. The second is the upward multilateral well including 10 branches (length: $100 \mathrm{~m}$, spacing: $75 \mathrm{~m}$, included angle between the branch and main wellbore in the $X-Y$ plane: $30^{\circ}$, and included angle between the branch and horizontal plane in the $X-Z$ plane: $42^{\circ}$ ) which are upward and out of the $X-Y$ plane.

Firstly, keep the producer as a conventional horizontal well and change the injector into a multilateral well, in order to enhance the performance of steam injection. Record the combination of the planar multilateral injector and horizontal producer as type $\mathrm{A}$, and record the combination of the upward multilateral injector and horizontal producer as type B. The results show that the performance of two multilateral well patterns is similar. For example, in the fourth distribution mode (permeability $=10 \mathrm{mD}$ and proportion $=30 \%$ ), 

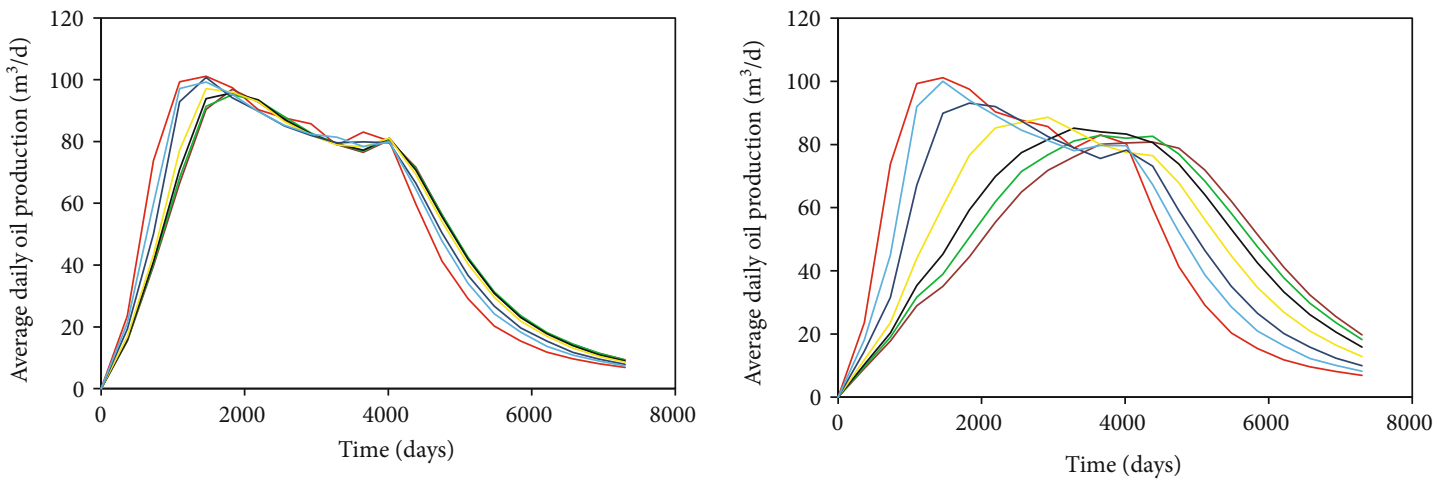

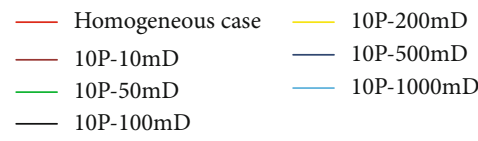

(a)

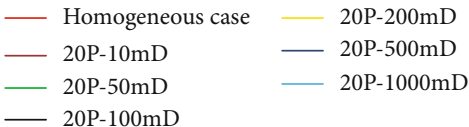

(b)

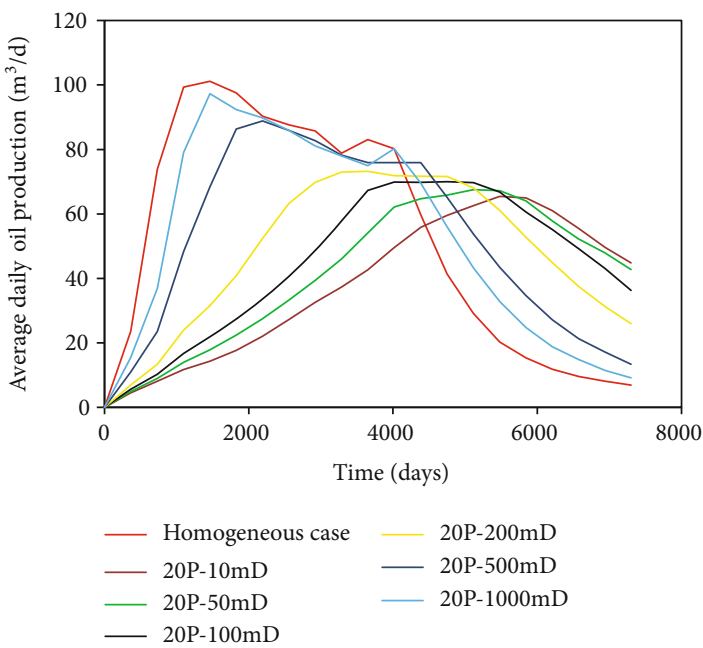

(c)

FIGURE 9: Average daily oil production with different proportion of the distribution and permeability of the muddy laminae (third distribution mode): (a) proportion $=10 \%$, (b) proportion $=20 \%$, and (c) proportion $=30 \%$.

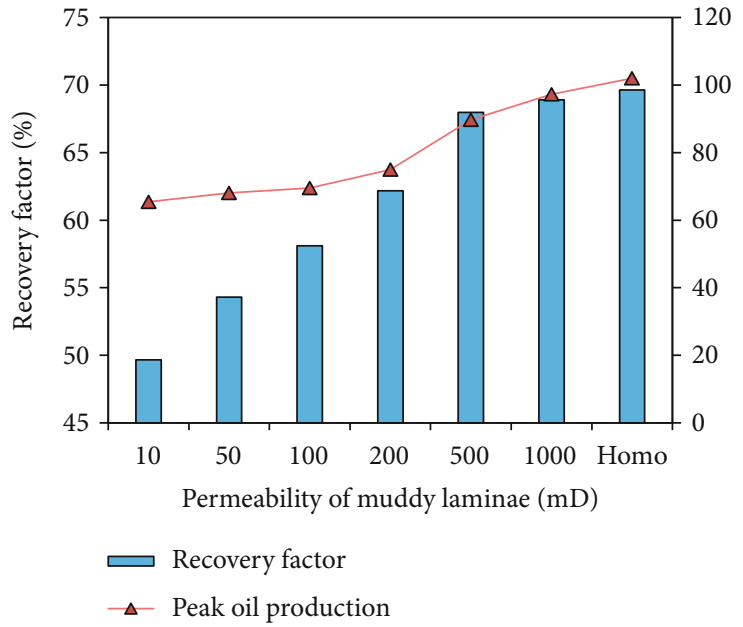

(a)

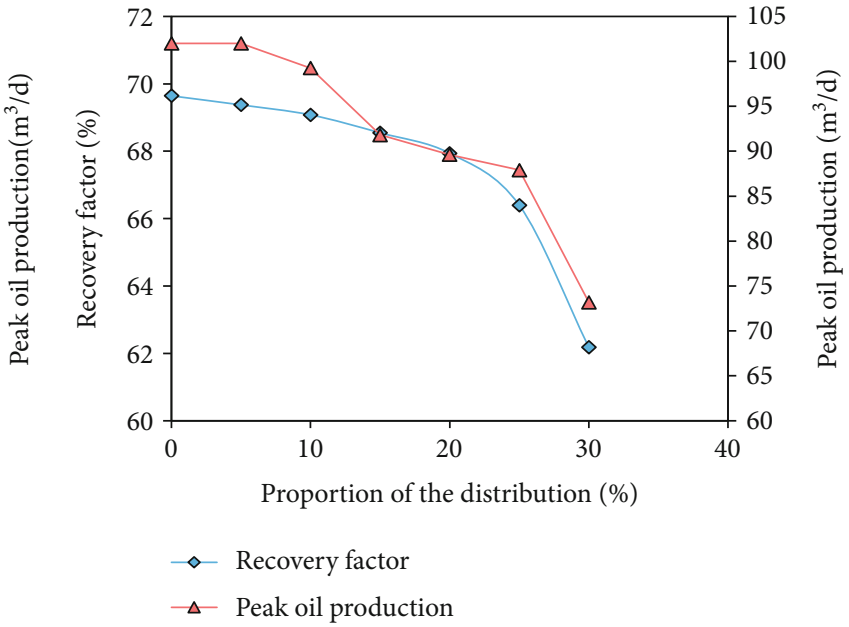

(b)

FIGURE 10: Recovery factor and peak oil production with different permeability and proportion of the distribution of the muddy laminae (third distribution mode): (a) different permeability (proportion $=30 \%$ ) and (b) different proportion (permeability $=200 \mathrm{mD}$ ). 


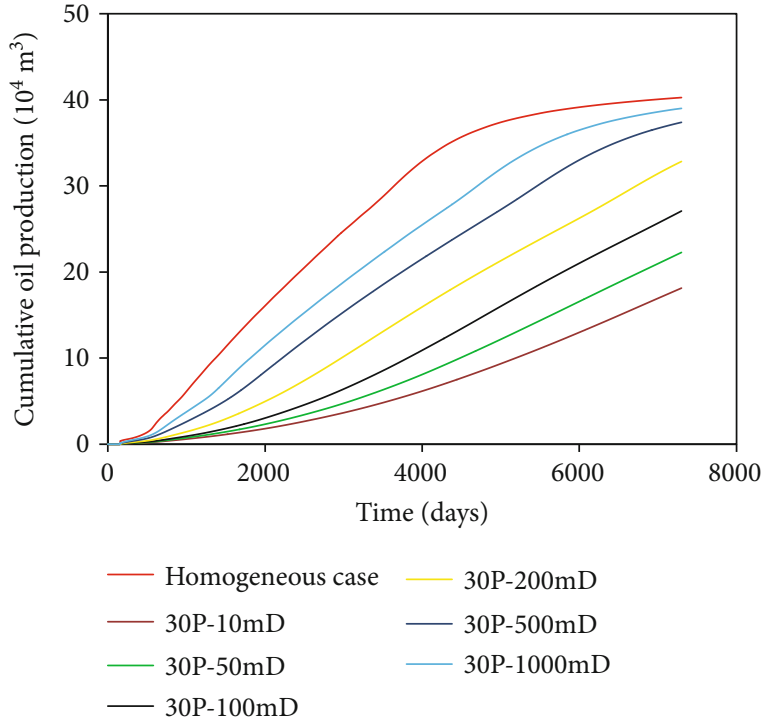

(a)
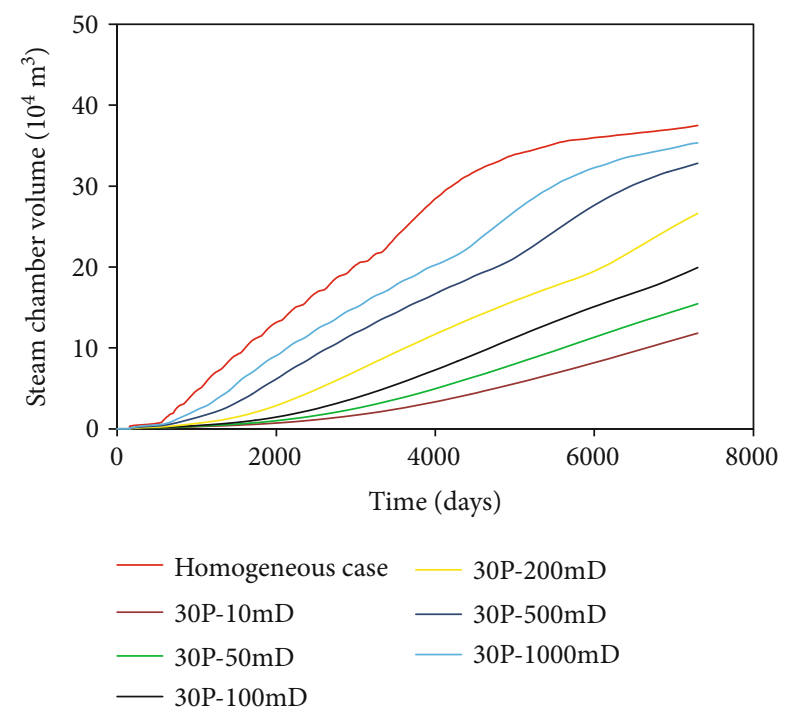

(c)

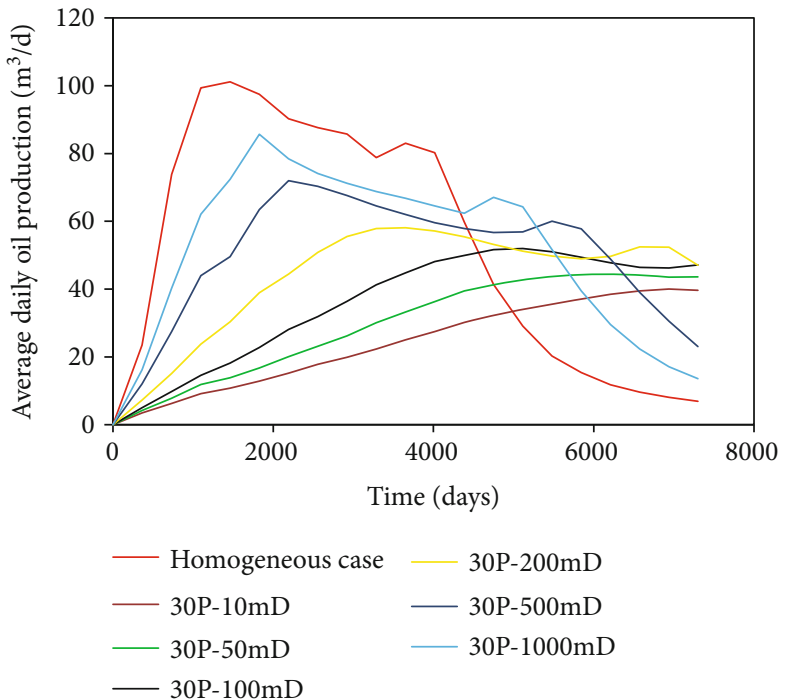

(b)
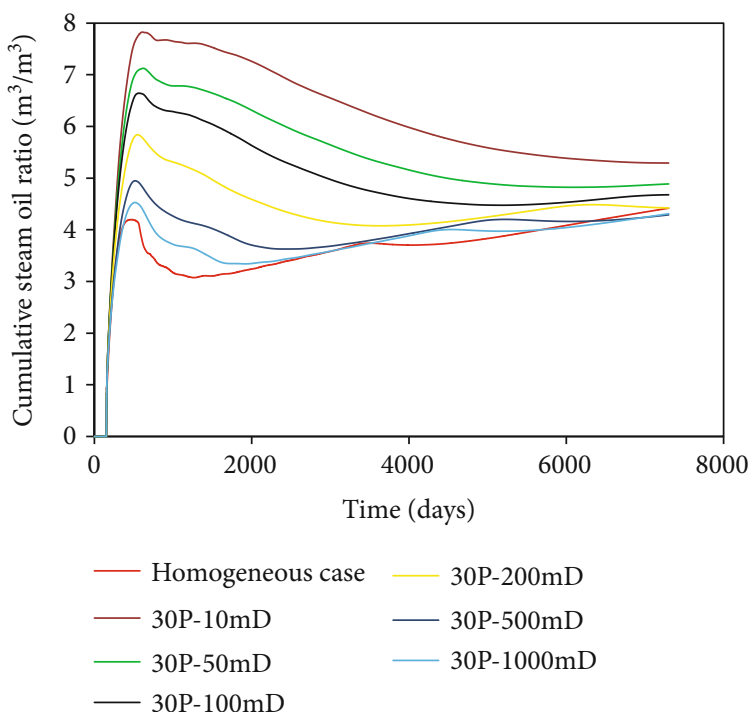

(d)

FIGURE 11: SAGD performance with different permeability of the muddy laminae (fourth distribution mode and proportion $=30 \%$ ): $(\mathrm{a})$ cumulative oil production, (b) average daily oil production, (c) steam chamber volume, and (d) cumulative steam oil ratio.

the recovery factor of type A and type B is $32.95 \%$ and $33.12 \%$, respectively, and the cumulative steam oil ratio of type $A$ and type $B$ is $5.22 \mathrm{~m}^{3} / \mathrm{m}^{3}$ and $5.15 \mathrm{~m}^{3} / \mathrm{m}^{3}$, respectively. Such kinds of well patterns increase the contact area between the injector and reservoir, which is helpful for the expansion of the steam chamber, so the performance is better than that of the conventional SAGD well pattern (recovery factor: $31.36 \%$, cumulative steam oil ratio: $\left.5.29 \mathrm{~m}^{3} / \mathrm{m}^{3}\right)$. The end part of the branch of the injector is beyond the muddy laminae when type $\mathrm{B}$ is adopted, so the performance is slightly better than that of type A.

Next, keep the injector as a conventional horizontal well and change the producer into a multilateral well, in order to enhance the performance of oil drainage. Record the combination of the horizontal injector and planar multilateral producer as type $\mathrm{C}$, and record the combination of the horizontal injector and upward multilateral producer as type D. The results also show that the performance of two multilateral well patterns is similar. For example, in the fourth distribution mode (permeability $=10 \mathrm{mD}$ and proportion $=$ $30 \%$ ), the recovery factor of type C and type D is $36.39 \%$ and $36.38 \%$, respectively, and the cumulative steam oil ratio of type $C$ and type $D$ is $4.89 \mathrm{~m}^{3} / \mathrm{m}^{3}$ and $5.19 \mathrm{~m}^{3} / \mathrm{m}^{3}$, respectively. Such kinds of well patterns increase the contact area between the producer and reservoir, which is helpful for oil drainage, so the performance is better than that of the conventional SAGD well pattern. But the performance of type $\mathrm{D}$ is worse than that of type $\mathrm{C}$, mainly because the risk of steam channeling is greater once type $\mathrm{D}$ is adopted.

Then, the researches on the combination of the multilateral injector and multilateral producer are conducted. Record the combination of the planar multilateral injector 

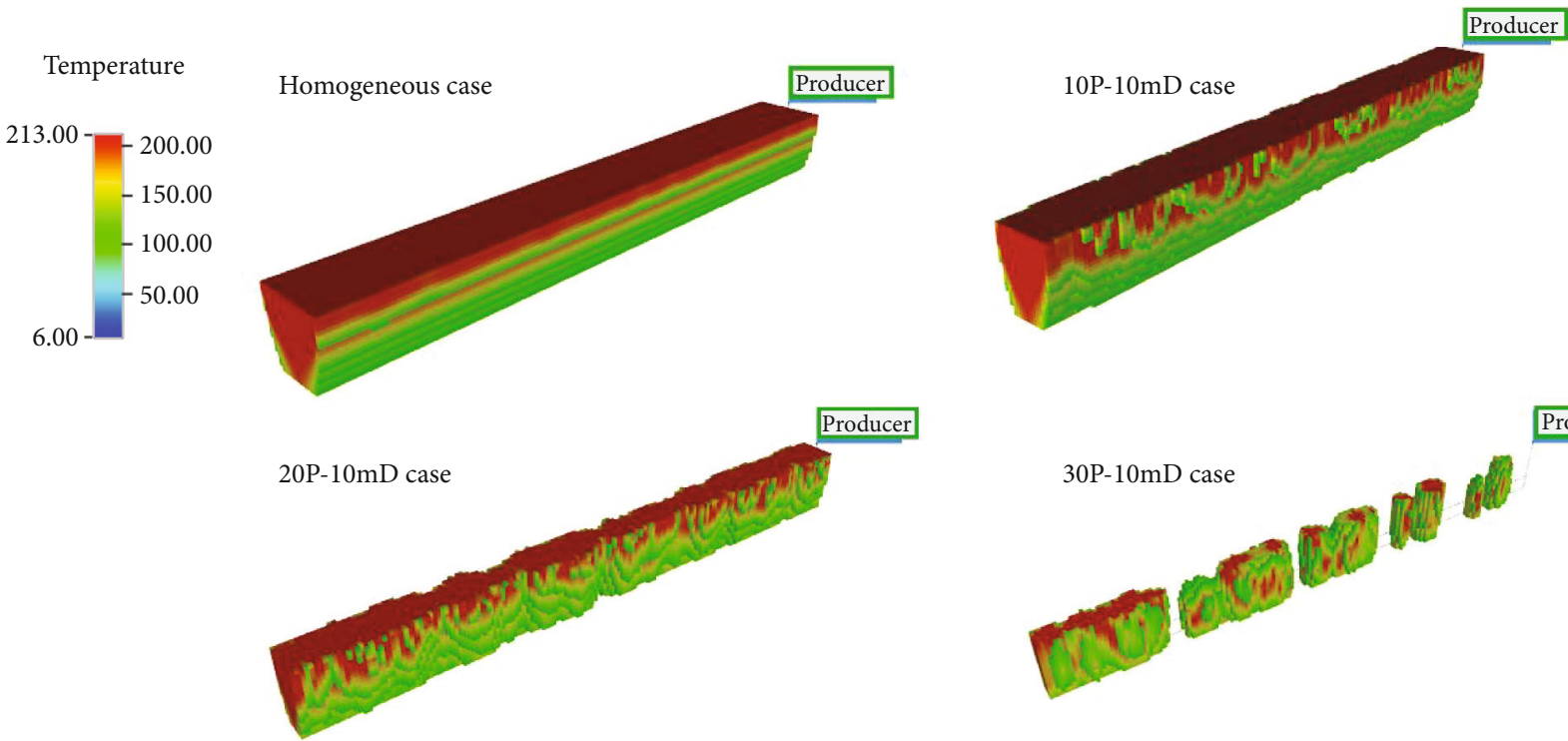

FIgURE 12: Three-dimensional expansion of the steam chamber with different cases (fourth distribution mode, after 8 years).

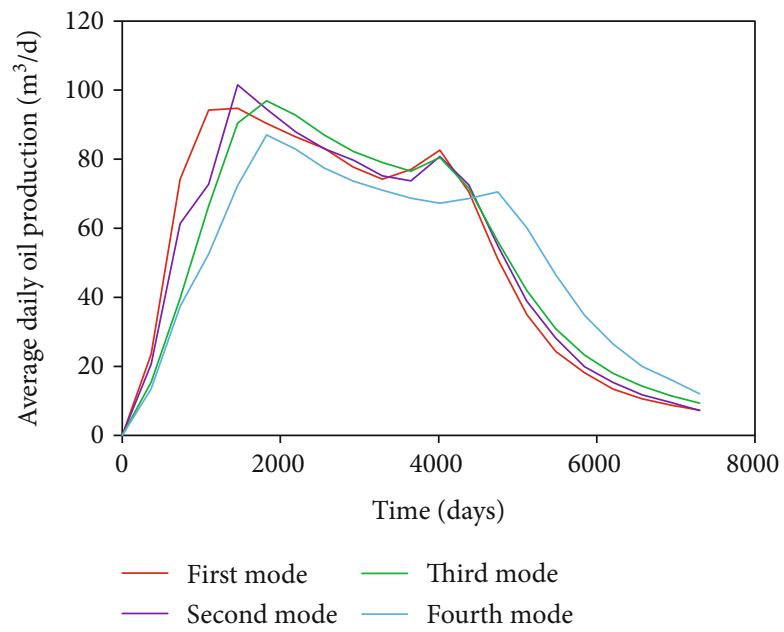

(a)

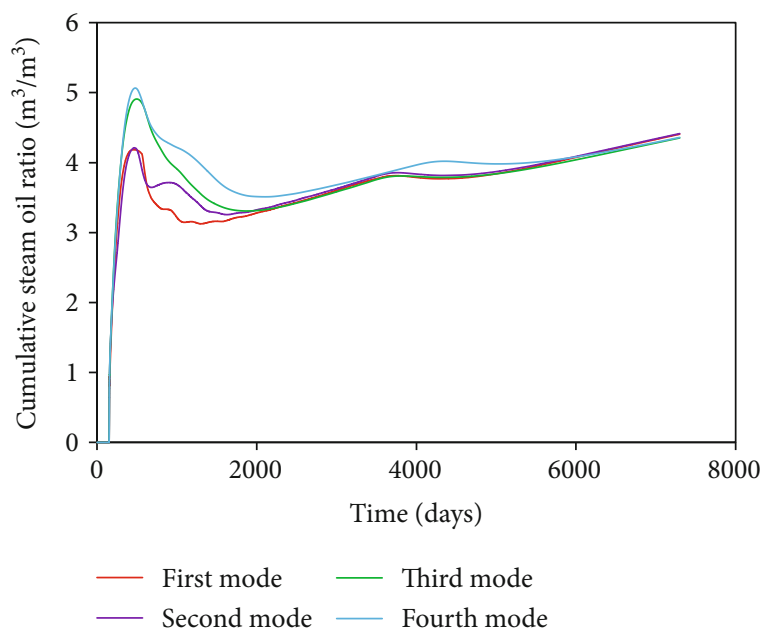

(b)

Figure 13: SAGD performance under different distribution modes (permeability $=10 \mathrm{mD}$ and proportion $=10 \%)$ : (a) average daily oil production and (b) cumulative steam oil ratio.

and planar multilateral producer as type E, and record the combination of the upward multilateral injector and planar multilateral producer as type $\mathrm{F}$. The results show that the performance of type $\mathrm{E}$ is better than that of type F. For example, in the fourth distribution mode (permeability $=10 \mathrm{mD}$ and proportion $=30 \%$ ), the recovery factor of type $\mathrm{E}$ and type $\mathrm{F}$ is $47.08 \%$ and $40.36 \%$, respectively, and the cumulative steam oil ratio of type $\mathrm{E}$ and type $F$ is $4.64 \mathrm{~m}^{3} / \mathrm{m}^{3}$ and $4.69 \mathrm{~m}^{3} / \mathrm{m}^{3}$, respectively. By adopting such kinds of well patterns, the channels of steam rising and oil drainage are increased simultaneously, so the performance is improved significantly. For type F, however, the heat connection between far ends of the branch within the injector and producer is difficult to form in the early stage of the SAGD process, due to the long distance between them. So the performance of type $\mathrm{F}$ is worse than that of type $\mathrm{E}$.
Therefore, take type A, type $\mathrm{C}$, and type $\mathrm{E}$ as examples for further analysis.

SAGD performance with different combinations of well patterns under different distribution modes of the muddy laminae is shown in Table 3. As shown in Table 3, if the muddy laminae are distributed above the injector (close to the injector), the improvement of SAGD performance is slight when the planar multilateral well pattern is adopted. So it is unnecessary to adopt the multilateral well pattern. However, if the muddy laminae are distributed between the injector and producer or the distribution mode is the combined distribution mode, SAGD performance will be significantly improved once the appropriate well pattern is adopted. For instance, the recovery factor can be increased by up to $15.72 \%$ and the cumulative steam oil ratio can be reduced by up to $0.65 \mathrm{~m}^{3} / \mathrm{m}^{3}$. 


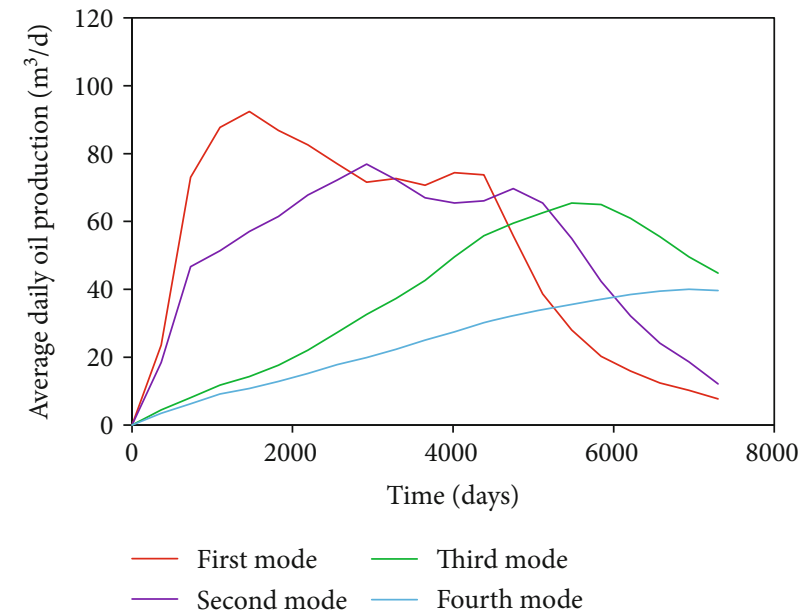

(a)

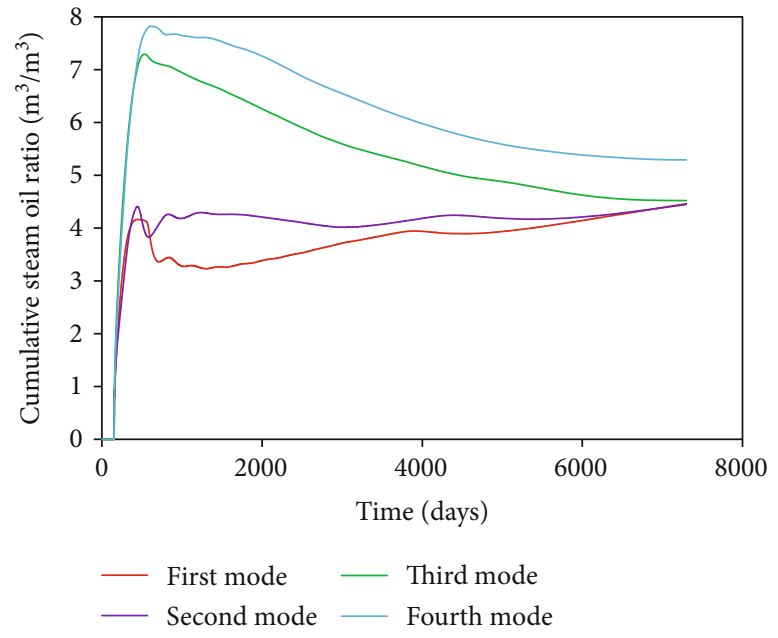

(b)

FIGURE 14: SAGD performance under different distribution modes (permeability $=10 \mathrm{mD}$ and proportion $=30 \%$ ): (a) average daily oil production and (b) cumulative steam oil ratio.

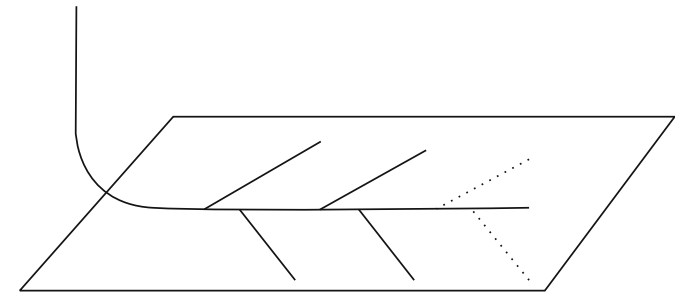

(a)

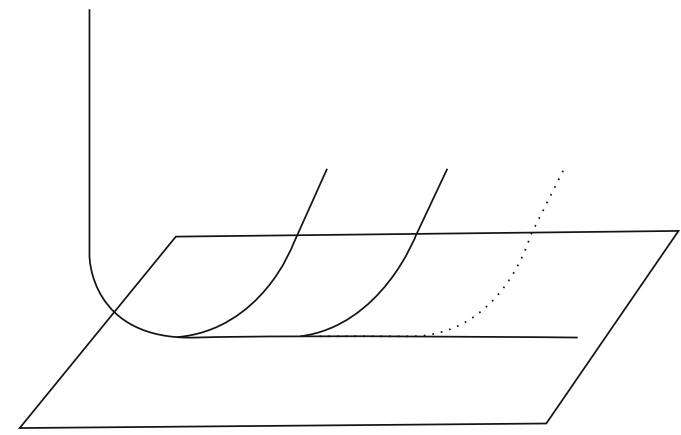

(b)

FIGURE 15: Schematic diagram of two multilateral well patterns: (a) planar multilateral well and (b) upward multilateral well.

TABLE 3: SAGD performance with different combinations of well patterns under different distribution modes of the muddy laminae (permeability $=10 \mathrm{mD}$ and proportion $=30 \%$ ).

\begin{tabular}{|c|c|c|c|}
\hline Distribution modes of the muddy laminae & $\begin{array}{l}\text { Different combinations of well } \\
\text { patterns }\end{array}$ & $\begin{array}{l}\text { Recovery factor } \\
(\%)\end{array}$ & $\begin{array}{l}\text { Cumulative steam oil ratio } \\
\qquad\left(\mathrm{m}^{3} / \mathrm{m}^{3}\right)\end{array}$ \\
\hline \multirow{4}{*}{$\begin{array}{l}\text { Muddy laminae are distributed above the injector (close } \\
\text { to the injector) }\end{array}$} & Conventional well pattern & 65.92 & 4.45 \\
\hline & Type A & 66.84 & 4.41 \\
\hline & Type C & 67.76 & 4.33 \\
\hline & Type E & 68.54 & 4.49 \\
\hline \multirow{4}{*}{$\begin{array}{l}\text { Muddy laminae are distributed between the injector and } \\
\text { producer }\end{array}$} & Conventional well pattern & 48.87 & 4.52 \\
\hline & Type A & 49.66 & 4.50 \\
\hline & Type C & 56.14 & 4.07 \\
\hline & Type E & 63.98 & 4.04 \\
\hline \multirow{4}{*}{ Combined distribution mode } & Conventional well pattern & 31.36 & 5.29 \\
\hline & Type A & 32.95 & 5.22 \\
\hline & Type C & 36.39 & 4.89 \\
\hline & Type E & 47.08 & 4.64 \\
\hline
\end{tabular}




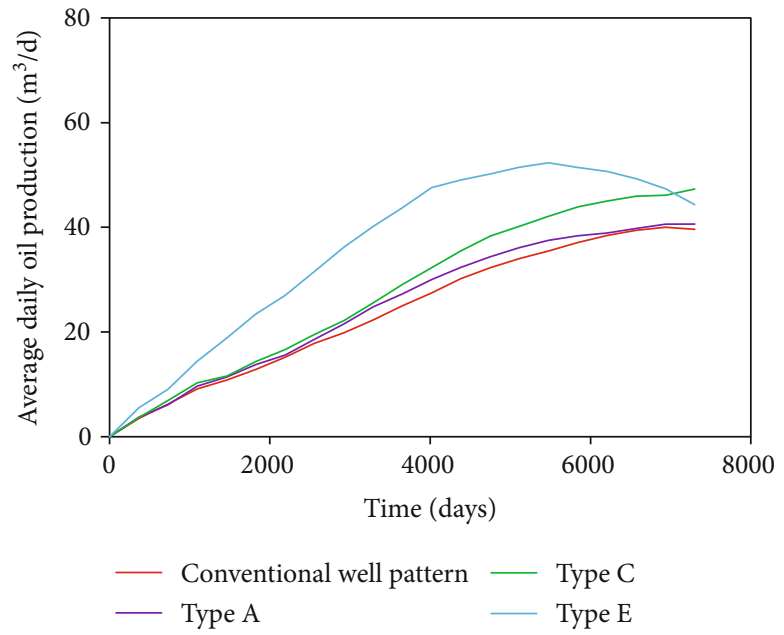

(a)

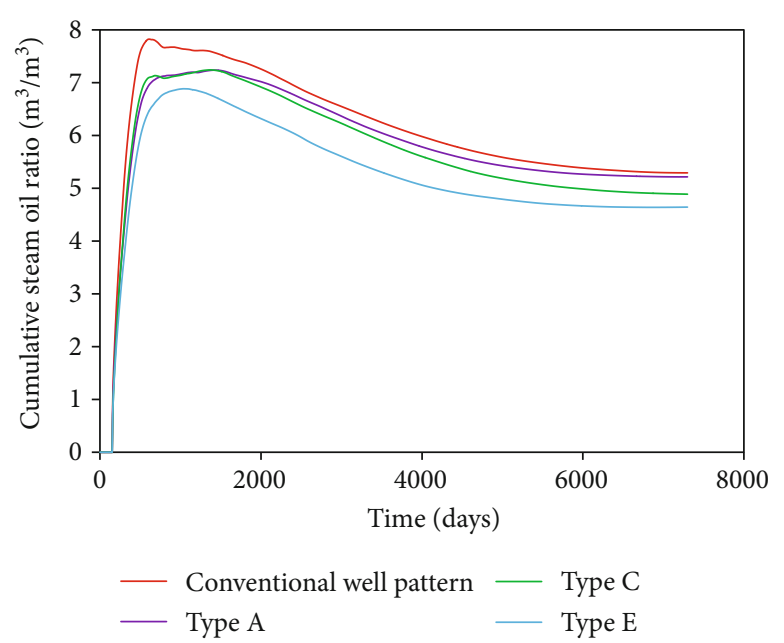

(b)

FIGURE 16: SAGD performance with different combinations of well patterns (combined distribution mode, permeability $=10 \mathrm{mD}$, and proportion $=30 \%$ ): (a) average daily oil production and (b) cumulative steam oil ratio.

Take the worst situation (combined distribution mode, permeability $=10 \mathrm{mD}$, and proportion $=30 \%$ ) as the example to analyze; SAGD performance with different combinations of well patterns is shown in Figure 16. It can be seen from Figure 16 that type $\mathrm{E}$ has the highest daily oil production and lowest cumulative steam oil ratio almost in the entire SAGD process. Comparing the temperature profiles after 10 years (as shown in Figure 17), it can be known that the branches of the planar multilateral well are very helpful for the expansion of the steam chamber under type E, once the heat connection between branches of the injector and producer could be well established. Unlike type A and type $\mathrm{C}$, the steam chamber of type E expands significantly faster than that of the conventional well pattern. For type $\mathrm{A}$ and type C, the SAGD performance is better than that of conventional well pattern, but the improvement is not significant, because the heat connection between branches within the injector or producer and the other well is not formed at the early stage of the SAGD process. Therefore, the increase in the expansion rate of the steam chamber is limited.

Figures 18(b) and 18(d) show that the existence of muddy laminae greatly hinders the expansion of the steam chamber and the oil drainage. But from Figures 18(a) and 18 (c), it can be seen that the area of the steam chamber and the oil drainage zone are bigger at the same time step, due to the effective utilization of the planar multilateral well. Figure 19 shows the comparison of oil saturation profiles after 15 years in the direction along the wellbore. Under type $\mathrm{E}$, although not every section has a great performance of oil drainage, the significant improvement can be seen compared with the conventional well pattern. The utilization of the planar multilateral well increases the contact area between the well and reservoir, especially the sand stone part within the reservoir. Therefore, the adverse effect brought by reservoir heterogeneities could be reduced effectively. Eventually, the more oil could be recovered from the reservoir, and the cumulative steam oil ratio is lower than that of the conven- tional well pattern, as the result of efficient utilization of injected steam.

\section{Summary and Conclusions}

(1) When the muddy laminae are existing in the formation, the steam chamber may expand slowly in some sections due to the poor capacity of heat and mass transfer, and the expansion of the steam chamber is relatively uneven along the wellbore. The influence level of the muddy laminae on conventional SAGD performance under different distribution modes is different, but the adverse effect is mainly reflected in the delay of peak oil production, the decrease in peak oil production, the decrease in steam chamber volume, and the increase in the cumulative steam oil ratio (mainly in early and middle stages of the SAGD process).

(2) The influence level of adverse impact of different modes in descending order is as follows: combined distribution mode $>$ muddy laminae are distributed between the injector and producer $>$ muddy laminae are distributed above the injector (close to the injector) > muddy laminae are distributed above the injector (close to the top of the formation). The muddy laminae distributed between the injector and producer, especially which are located at the middle part of the injector and producer, seriously affect the preheating effect in the start-up stage.

(3) When the muddy laminae are distributed above the injector (close to the top of the formation), the performance indicators change slightly, no matter how the conditions change within the scope of the study. For other modes, if the permeability of muddy laminae is high or the proportion of the distribution of 

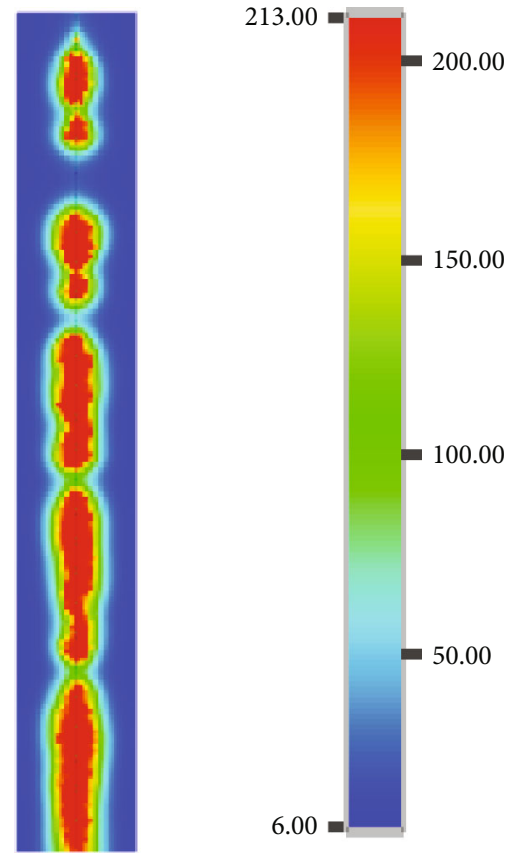

(a)

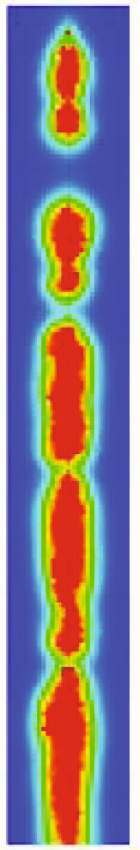

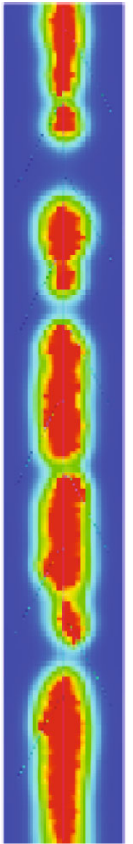

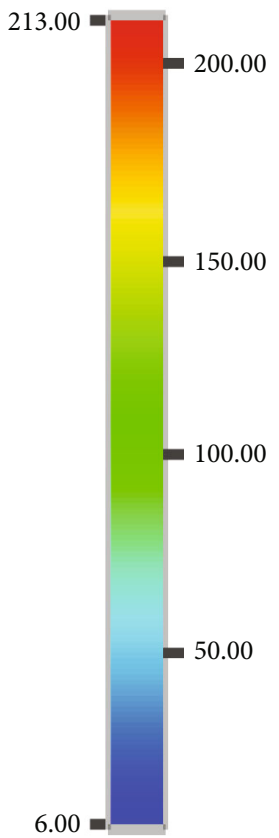

(b)

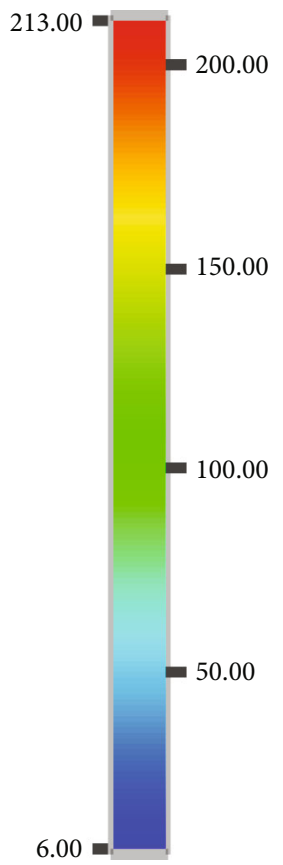

(d)

FIgure 17: Temperature profiles after 10 years (K layer: 13; unit: $\left.{ }^{\circ} \mathrm{C}\right)$ : (a) conventional well pattern, (b) type A, (c) type C, and (d) type E.

muddy laminae is relatively low, the influence degree is also small.

(4) If the muddy laminae are distributed above the injector, it is unnecessary to adopt the multilateral well pattern. If the muddy laminae are distributed between the injector and producer or the distribution mode is the combined distribution mode, SAGD performance can be significantly improved once the combination of the pla- nar multilateral injector and planar multilateral producer is adopted. Under the combined distribution mode of muddy laminae, the recovery factor can be increased by $15.72 \%$ and the cumulative steam oil ratio can be reduced by $0.65 \mathrm{~m}^{3} / \mathrm{m}^{3}$.

(5) It can be known that the branches of the planar multilateral well are very helpful for the expansion of the steam chamber and oil drainage, once the 


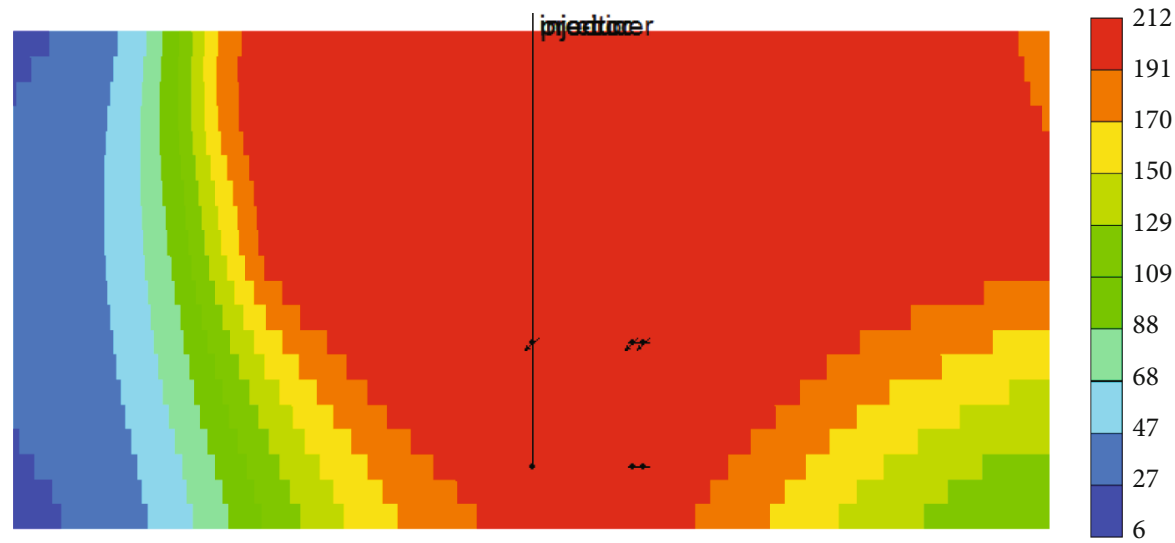

(a)

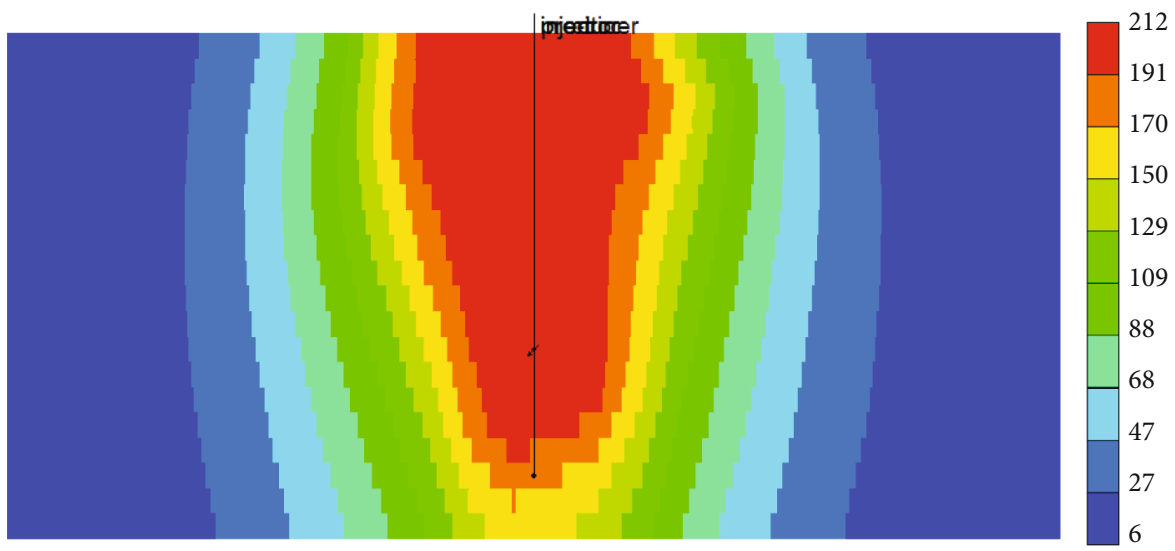

(b)
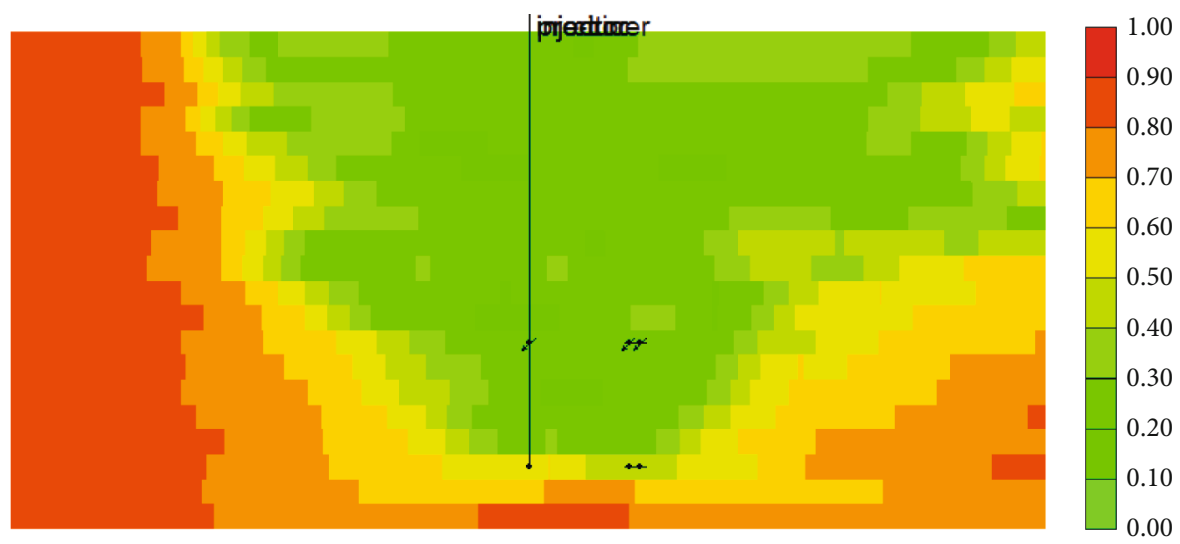

(c)

Figure 18: Continued. 


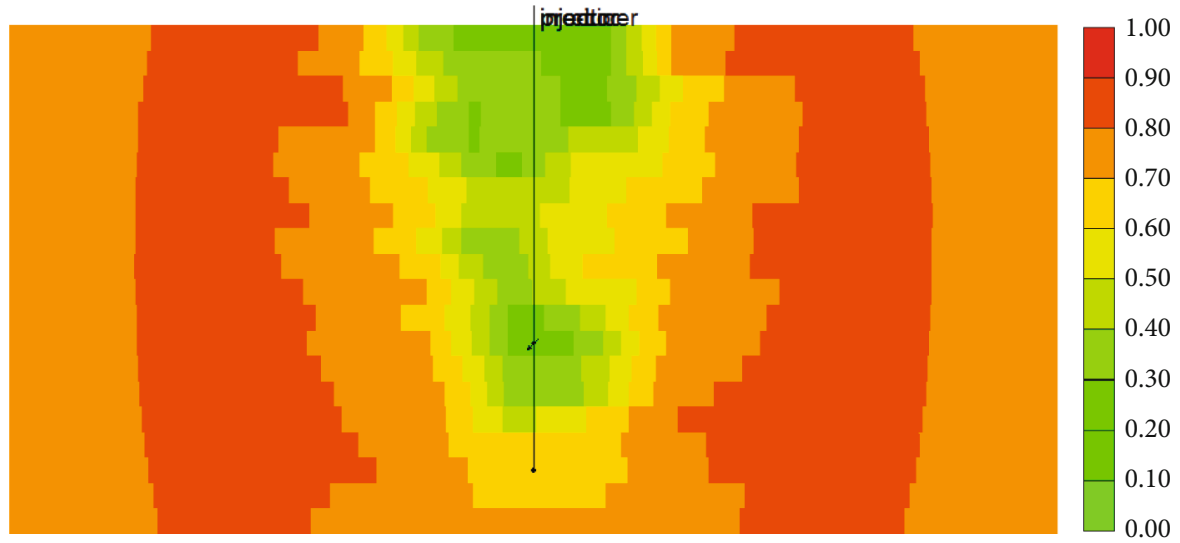

(d)

Figure 18: Temperature profiles after 15 years (J layer: 39; unit: $\left.{ }^{\circ} \mathrm{C}\right)$ : (a) conventional well pattern and (b) type E. Oil saturation profiles after 15 years (J layer: 39; unit: fraction): (c) conventional well pattern and (d) type E.
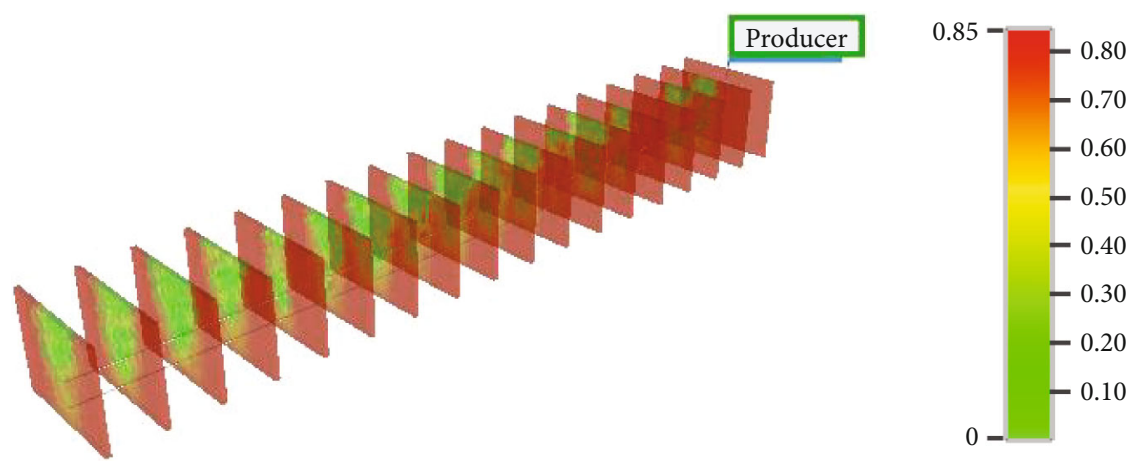

(a)
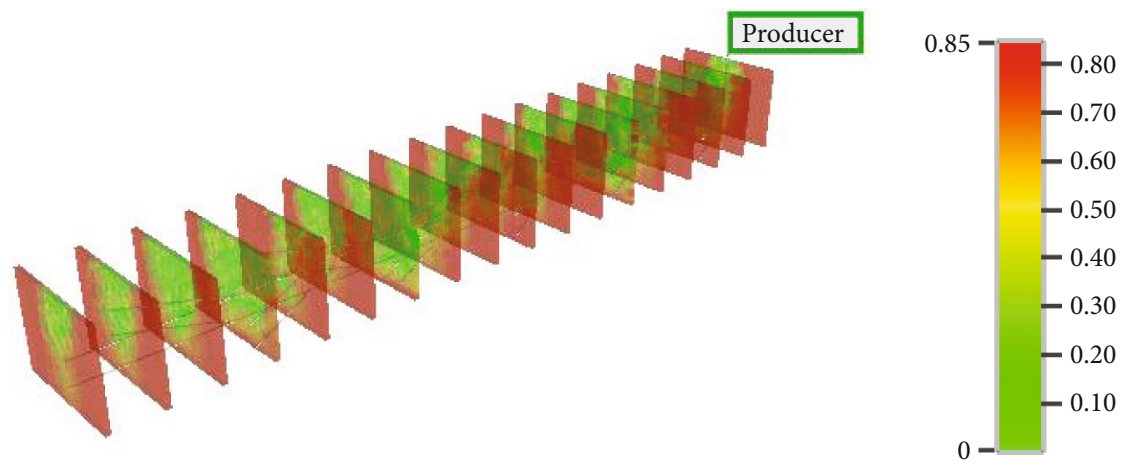

(b)

FIGURE 19: Oil saturation profiles after 15 years (along the wellbore; unit: fraction): (a) conventional well pattern and (b) type E.

heat connection between branches of the injector and producer is well established. Overall results show that the multilateral well pattern is promising for SAGD applications at oil sands or heavy oil reservoirs which are rich in muddy laminae. In our study, two different multilateral well patterns with certain design parameters are selected to improve SAGD performance. However, there are still many types of multilateral well patterns, and the design parameters, such as length and spacing, also have a variety of combinations. In the future, more research works which are related to the design and optimization of the multilateral well pattern should be done, in order to further improve the SAGD performance at oil sands or heavy oil reservoirs which are rich in muddy laminae.

\section{Nomenclature}

$\mathbf{u}_{i}: \quad$ Velocity of phase $i(\mathrm{~m} / \mathrm{s})$

$\mathbf{K}_{i}$ : $\quad$ Effective permeability tensor of phase $i$ in porous media $\left(\mathrm{m}^{2}\right)$ 
$\nabla \boldsymbol{\Phi}_{i}:$ The potential gradient which includes pressure and gravity

$z: \quad$ The elevation above the datum location (m)

$g: \quad$ Acceleration of gravity $\left(\mathrm{m} / \mathrm{s}^{2}\right)$

$P: \quad$ Pressure $\left(\mathrm{kg} /\left(\mathrm{m} \cdot \mathrm{s}^{2}\right)\right)$

$\rho: \quad$ Density of fluid $\left(\mathrm{kg} / \mathrm{m}^{3}\right)$

$\mathbf{k}_{\mathrm{th}}$ : Thermal conductivity tensor $(\mathrm{W} /(\mathrm{m} \cdot \mathrm{K}))$

$T: \quad$ Temperature (K)

$K_{\text {abs }}$ : Absolute permeability of reservoir rock $\left(\mathrm{m}^{2}\right)$

$K_{\text {ro }}$ : Relative permeability of the oil phase

$K_{\mathrm{rw}}$ : Relative permeability of the water phase

$K_{\mathrm{rg}}$ : Relative permeability of the gas phase

$B_{0}$ : Volume factor of the oil phase

$B_{\mathrm{w}}$ : Volume factor of the water phase

$B_{\mathrm{g}}$ : Volume factor of the gas phase

$R_{\mathrm{so}}$ : Solution-gas ratio in oil phases $\left(\mathrm{m}^{3} / \mathrm{m}^{3}\right)$

$R_{\mathrm{sw}}$ : Solution-gas ratio in water phases $\left(\mathrm{m}^{3} / \mathrm{m}^{3}\right)$

$S_{\mathrm{o}}$ : $\quad$ Saturation of the oil phase

$S_{\mathrm{w}}$ : Saturation of the water phase

$S_{\mathrm{g}}$ : $\quad$ Saturation of the gas phase

$q_{\mathrm{o}}$ : Flow rates of the oil phase $\left(\mathrm{m}^{3} / \mathrm{s}\right)$

$q_{\mathrm{fg}}$ : Flow rates of free gas $\left(\mathrm{m}^{3} / \mathrm{s}\right)$

$h_{i}$ : $\quad$ Enthalpy of each phase (J)

$M_{\mathrm{r}}$ : Volumetric heat capacity of the reservoir rocks $(\mathrm{J} /(\mathrm{kg} \cdot \mathrm{K}))$

$T_{\text {ref }}$ : Reference temperature (K)

$U_{0}:$ Specific internal energies of the oil phase $(\mathrm{J} / \mathrm{kg})$

$U_{\mathrm{w}}:$ Specific internal energies of the water phase $(\mathrm{J} / \mathrm{kg})$

$U_{\mathrm{g}}: \quad$ Specific internal energies of the gas phase $(\mathrm{J} / \mathrm{kg})$

$Q_{I}:$ Input energy $\left(J /\left(\mathrm{m}^{3} \cdot \mathrm{s}\right)\right)$.

\section{Data Availability}

The data used to support the findings of this study are included within the article.

\section{Conflicts of Interest}

The authors declare that they have no conflicts of interest.

\section{Acknowledgments}

This work has been supported by the Department of America E\&P, Research Institute of Petroleum Exploration and Development, PetroChina. The authors would like to acknowledge Computer Modeling Group (CMG) Company for providing the academic licenses for STARS. Finally, we gratefully acknowledge the financial support from the National Science and Technology Major Project of China (Grant No. 2016ZX05031).

\section{References}

[1] Y. Li, Y. Chen, W. Pu et al., "Low temperature oxidation characteristics analysis of ultra-heavy oil by thermal methods," Journal of Industrial \& Engineering Chemistry, vol. 48, pp. 249-258, 2017.
[2] J. Jimenez, "The field performance of SAGD projects in Canada," in International Petroleum Technology Conference, pp. 1-11, Kuala Lumpur, Malaysia, 2008.

[3] X. Sun, J. Cai, X. Li, W. Zheng, T. Wang, and Y. Zhang, "Experimental investigation of a novel method for heavy oil recovery using supercritical multithermal fluid flooding," Applied Thermal Engineering, vol. 185, article 116330, 2021.

[4] M. Irani, N. Sabet, and F. Bashtani, "Horizontal producers deliverability in SAGD and solvent aided-SAGD processes: pure and partial solvent injection," Fuel, vol. 294, article 120363, 2021.

[5] R. Butler, "Steam-assisted gravity drainage: concept, development, performance and future," Journal of Canadian Petroleum Technology, vol. 33, no. 2, pp. 44-50, 1994.

[6] A. M. Al-Bahlani and T. Babadagli, "SAGD laboratory experimental and numerical simulation studies: a review of current status and future issues," Journal of Petroleum Science and Engineering, vol. 68, no. 3-4, pp. 135-150, 2009.

[7] D. Ji, H. Zhong, M. Dong, and Z. Chen, "Study of heat transfer by thermal expansion of connate water ahead of a steam chamber edge in the steam-assisted-gravity-drainage process," Fuel, vol. 150, pp. 592-601, 2015.

[8] S. M. Ali, "Life after SAGD - 20 years later," in SPE Western Regional Meeting, pp. 1-7, Anchorage, USA, 2016.

[9] X. Qu, Y. Li, S. Li, J. Wang, H. Xu, and Z. Li, "Thermal cracking, aquathermolysis, and their upgrading effects of Mackay River oil sand," Journal of Petroleum Science and Engineering, vol. 201, article 108473, 2021.

[10] H. Chen, Z. Wang, K. Wang, Z. Li, and S. Li, "Investigation of EOR mechanism for flue gas assisted SAGD," Journal of Petroleum Science and Engineering, vol. 193, article 107420, 2020.

[11] J. Zheng, J. Leung, R. Sawatzky, and J. Alvarez, “A cluster-based approach for visualizing and categorizing the impacts of shale barrier configurations on SAGD production," Journal of Petroleum Science and Engineering, vol. 203, article 108664, 2021.

[12] C. Wang and J. Leung, "Characterizing the effects of lean zones and shale distribution in steam-assisted-gravity-drainage recovery performance," SPE Reservoir Evaluation \& Engineering, vol. 18, no. 3, pp. 329-345, 2015.

[13] Z. Ma and J. Leung, "A knowledge-based heterogeneity characterization framework for 3D steam-assisted gravity drainage reservoirs," Knowledge-Based Systems, vol. 192, article 105327, 2020.

[14] G. Yang and R. Butler, "Effects of reservoir heterogeneities on heavy oil recovery by steam-assisted gravity drainage," Journal of Canadian Petroleum Technology, vol. 31, pp. 37-43, 1992.

[15] H. Shin and J. Choe, "Shale barrier effects on the SAGD performance,", in SPE/EAGE Reservoir Characterization and Simulation Conference, pp. 1-10, Abu Dhabi, UAE, 2009.

[16] H. Wang, "Research and discuss on key parameters of steam flooding and gravity drainage tridimensional development in super heavy oil reservoir," Journal of Southwest Petroleum University (Science \& Technology Edition), vol. 36, pp. 93100, 2014.

[17] Y. Xia, S. Huang, X. Chen, M. Cao, and L. Yang, "Study on the characteristics of production performance and steam chamber of SAGD considering interlayer," in SPE International Heavy Oil Conference and Exhibition, pp. 1-11, Kuwait City, Kuwait, 2018.

[18] S. Huang, L. Yang, Y. Xia, M. Du, and Y. Yang, “An experimental and numerical study of a steam chamber and 
production characteristics of SAGD considering multiple barrier layers," Journal of Petroleum Science and Engineering, vol. 180, pp. 716-726, 2019.

[19] Z. Ma and J. Leung, "Integration of data-driven modeling techniques for lean zone and shale barrier characterization in SAGD reservoirs," Journal of Petroleum Science and Engineering, vol. 176, pp. 716-734, 2019.

[20] Q. Wang, X. Gao, C. Luo, X. Meng, S. Gan, and J. Liu, "Interlayer development patterns and SAGD enhanced oil recovery technology in the super heavy oil category-III reservoir," Special Oil and Gas Reservoirs, vol. 27, pp. 105-112, 2020.

[21] W. Liu, H. Zhang, B. Du, R. Zhao, and Y. Pan, "Influences of the interlayers in heterogeneous reservoirs on SAGD development and the technical countermeasures," Oil Drilling \& Production Technology, vol. 42, pp. 236-241, 2020.

[22] A. Kumar and H. Hassanzadeh, "Impact of shale barriers on performance of SAGD and ES-SAGD - a review," Fuel, vol. 289, article 119850, 2021.

[23] M. Kim and H. Shin, "Numerical simulation of undulating shale breaking with steam-assisted gravity drainage (UBSAGD) for the oil sands reservoir with a shale barrier," Journal of Petroleum Science and Engineering, vol. 195, article 107604, 2020.

[24] G. Ipek, T. Frauenfeld, and J. Y. Yuan, "Numerical study of shale issues in SAGD," in Canadian International Petroleum Conference, pp. 1-21, Calgary, Alberta, 2008.

[25] Y. Wu, X. Li, Y. Jiang, H. Wang, and W. He, "Reservoir simulation of shale barrier failure in heterogeneous SAGD reservoirs: a case study," in SPE Reservoir Characterization and Simulation Conference and Exhibition, pp. 1-14, Abu Dhabi, UAE, 2013.

[26] Z. Wang, Z. Li, H. Sarma et al., “A visualization experimental study on gas penetration through interlayer to improve SAGD performance," Journal of Petroleum Science and Engineering, vol. 177, pp. 959-970, 2019.

[27] Y. Wu, X. Liu, X. Du et al., "Scaled physical experiments on drainage mechanisms of solvent-expanded SAGD in superheavy oil reservoirs," Petroleum Exploration and Development, vol. 47, no. 4, pp. 820-826, 2020.

[28] K. Mohammadi and F. Ameli, "Toward mechanistic understanding of fast SAGD process in naturally fractured heavy oil reservoirs: application of response surface methodology and genetic algorithm," Fuel, vol. 253, pp. 840-856, 2019.

[29] X. Sun, Z. Song, L. Cai, Y. Zhang, and P. Li, "Phase behavior of heavy oil-solvent mixture systems under reservoir conditions," Petroleum Science, vol. 17, no. 6, pp. 1683-1698, 2020.

[30] R. R. MacDonald and D. M. Erickson, "Demands of multilateral wells functions," in SPE/CIM Seventh One-Day Conference on Horizontal Well Technology, pp. 1-8, Calgary, Alberta, 1999.

[31] X. Gao, Y. Zhang, Y. Huang, Y. Ma, Y. Zhao, and Q. Liu, "Study on heat extraction considering the number and orientation of multilateral wells in a complex fractured geothermal reservoir," Renewable Energy, vol. 177, pp. 833-852, 2021.

[32] A. Garrouch, H. Lababidi, and A. Ebrahim, "An integrated approach for the planning and completion of horizontal and multilateral wells," Journal of Petroleum Science and Engineering, vol. 44, no. 3-4, pp. 283-301, 2004.

[33] D. Denney, "Subsea smart multilateral wells increase reserves at Gullfaks South Statfjord," Journal of Canadian Petroleum Technology, vol. 58, no. 8, pp. 51-52, 2006.
[34] D. Zhu and D. Arcos, "Technical and economical analysis of multilateral well applications," in SPE Russian Oil and Gas Technical Conference and Exhibition, pp. 1-17, Moscow, Russia, 2008.

[35] V. Sesetty and A. Ghassemi, "A numerical study of sequential and simultaneous hydraulic fracturing in single and multilateral horizontal wells," Journal of Petroleum Science and Engineering, vol. 132, pp. 65-76, 2015.

[36] M. Alyan and A. Sowaidi, "Assessment of fishbone well design performance in a tight carbonate compared to single extralong MRC lateral," in Abu Dhabi International Petroleum Exhibition \& Conference, pp. 1-15, Abu Dhabi, UAE, 2019.

[37] M. Rylance, Y. Tuzov, S. Aliyev et al., "Fishbones, wishbones and birch-leaves, multilateral well design on the Srednebotuobinskoye field in Eastern Siberia," in SPE Russian Petroleum Technology Conference, pp. 1-20, Moscow, Russia, 2020.

[38] P. Liu, Y. Zhou, P. Liu, L. Shi, X. Li, and L. Li, "Numerical study of herringbone injector-horizontal producer steam assisted gravity drainage (HI-SAGD) for extra-heavy oil recovery," Journal of Petroleum Science and Engineering, vol. 181, article 106227, 2019.

[39] CMG STARS ${ }^{\mathrm{TM}}$, User's Manual; Version 2020, Computer Modelling Group Ltd., Calgary, AB, Canada, 2020.

[40] J. Wang and I. D. Gates, "Identifying reservoir features via iSOR response behaviour,” Energies, vol. 14, no. 2, p. 427, 2021.

[41] Y. Bao, J. Wang, and I. D. Gates, "On the physics of cyclic steam stimulation,” Energy, vol. 115, pp. 969-985, 2016.

[42] J. Wang and I. D. Gates, "Time scales for steam injection and bitumen production in steam-assisted gravity drainage," Energy, vol. 227, article 120430, 2021.

[43] G. Liang, S. Liu, H. Chen, Y. Liu, and Y. Luo, "Shale layers issues in oil sands SAGD process," Science Technology and Engineering, vol. 15, pp. 68-73, 2015. 